\title{
A numerical analysis of biogeochemical controls with physical modulation on hypoxia during summer in the Pearl River estuary
}

\author{
Bin Wang, Jiatang Hu, Shiyu Li, and Dehong Liu \\ Guangdong Provincial Key Laboratory of Environmental Pollution Control and Remediation Technology, School of \\ Environmental Science and Engineering, Sun Yat-sen University, Guangzhou, 510275, China \\ Correspondence to: Jiatang Hu (jiatanghu@126.com) and Shiyu Li (eeslsy@mail.sysu.edu.cn)
}

Received: 21 October 2016 - Discussion started: 21 November 2016

Revised: 10 April 2017 - Accepted: 11 May 2017 - Published: 20 June 2017

\begin{abstract}
A three-dimensional (3-D) physicalbiogeochemical coupled model was applied to explore the mechanisms controlling the dissolved oxygen (DO) dynamics and bottom hypoxia during summer in the Pearl River estuary (PRE). By using the numerical oxygen tracers, we proposed a new method (namely the physical modulation method) to quantify the contributions of boundary conditions and each source and sink process occurring in local and adjacent waters to the DO conditions. A mass balance analysis of DO based on the physical modulation method indicated that the DO conditions at the bottom layer were mainly controlled by the source and sink processes, among which the sediment oxygen demand (SOD) at the water-sediment interface and the re-aeration at the air-sea interface were the two primary processes determining the spatial extent and duration of bottom hypoxia in the PRE. The SOD could cause a significant decrease in the bottom DO concentrations (averaged over July-August 2006) by over $4 \mathrm{mg} \mathrm{L}^{-1}$ on the shelf off the Modaomen sub-estuary, leading to the formation of a high-frequency zone of hypoxia (HFZ). However, the hypoxia that occurred in the HFZ was intermittent and distributed in a small area due to the combined effects of re-aeration and photosynthesis, which behaved as sources for DO and offset a portion of the DO consumed by SOD. The bottom DO concentrations to the west of the lower Lingdingyang Bay (i.e. the western shoal near Qi'ao Island) were also largely affected by high SOD, but there was no hypoxia occurring there because of the influence of re-aeration. Specifically, re-aeration could lead to an increase in the bottom DO concentrations by $\sim 4.8 \mathrm{mg} \mathrm{L}^{-1}$ to the west of the lower Lingdingyang Bay. The re-aeration led to a strong vertical DO gradient
\end{abstract}

between the surface and the lower layers. As a result, the majority ( $~ 89 \%)$ of DO supplemented by re-aeration was transported to the lower layers through vertical diffusion and $\sim 28 \%$ reached the bottom eventually. Additional numerical experiments showed that turning off re-aeration could lead to an expansion of the hypoxic area from 237 to $2203 \mathrm{~km}^{2}$ and result in persistent hypoxia (hypoxic frequency $>80 \%$ ) to the west of the lower Lingdingyang Bay. Compared to re-aeration and SOD, photosynthesis and water column respiration had relatively small impacts on the DO conditions; turning off these two processes increased the hypoxic area to $591 \mathrm{~km}^{2}$. In summary, our study explicitly elucidated the interactive impacts of physical and biogeochemical processes on the DO dynamics in the PRE, which is critical to understanding hypoxia in this shallow and river-dominated estuarine system.

\section{Introduction}

The formation and maintenance of hypoxia are related to physical and biogeochemical processes. Physical processes can affect dissolved oxygen (DO) conditions by changing the horizontal and vertical DO transport fluxes. For example, hypoxia in the Changjiang estuary is related to the inflow of the Taiwan Warm Current, which brings low-oxygen waters to the estuary and facilitates stratification, inhibiting vertical diffusion and thus isolating the bottom waters from the oxygenated surface waters (Wang, 2009; Wang et al., 2012). Other studies have also suggested that stratification was the major cause of hypoxia in many areas (Ni et al., 2014; Du and Shen, 2015; Yu et al., 2015a). Biogeochemical processes can 
have a significant impact on DO as well by affecting its internal production and consumption. For example, phytoplankton growth can be stimulated by excessive nutrient loading producing abundant DO by photosynthesis in the water column. In addition, phytoplankton utilize DO for respiration during their growth and generate detrital organic matter after death that can deposit on the sediment and result in sediment oxygen demand (SOD). The statistical linkage between nutrient loadings and the spatial extent of hypoxia was well documented for the Chesapeake Bay (Hagy et al., 2004) and the northern Gulf of Mexico (Justic et al., 2003). In some coastal areas, the terrestrial inputs of particulate organic matter are important to the formation of hypoxia. Zhang and $\mathrm{Li}$ (2010) suggested that terrestrial particulate organic carbon played a significant role in generating high SOD, which is the main cause of hypoxia in the Pearl River estuary (PRE). Furthermore, physical and biogeochemical processes are closely coupled and highly interacted with each other in regulating the DO dynamics. Physical processes can affect the DO concentrations by altering the distribution of nutrients and phytoplankton and their relevant biogeochemical processes that can affect the DO fluxes by producing or consuming DO along with the physical transport. One important question concerning hypoxia is to elucidate the relative contributions of physical and biogeochemical processes. A mass balance analysis on DO is a commonly used method, widely applied to many hypoxic areas including the Chesapeake Bay and the northern Gulf of Mexico to address this question (Scully, 2010; Montes et al., 2014; Li et al., 2015; Yu et al., 2015b).

The Pearl River is the second largest river in China with an annual discharge rate of $10524 \mathrm{~m}^{3} \mathrm{~s}^{-1}, 80 \%$ of which is transported during the wet season (Ou et al., 2009; Zhang and Li, 2010). The Pearl River network (Fig. 1) includes Beijiang (North River), Xijiang (West River), Dongjiang (East River), Liuxi River, and Tan River, covering a drainage area of $4.5 \times 10^{5} \mathrm{~km}^{2}$. Freshwater from the river network is emptied into the northern South China Sea (NSCS) through eight outlets: Humen, Jiaomen, Hongqili, Hengmen, Modaomen, Jitimen, Hutiaomen, and Yamen. The PRE (Fig. 1) is located in the NSCS and adjacent to the river network. The PRE consists of four sub-estuaries, including the Lingdingyang Bay, Modaomen, Jitimen, and Huangmaohai sub-estuaries, among which the Lingdingyang Bay is the largest one with an area of almost $2000 \mathrm{~km}^{2}$. The PRE is a complex estuarine system characterized by a shallow bank to the west of the estuary with a depth of less than $5 \mathrm{~m}$ and two deep channels with depths larger than $10 \mathrm{~m}$ and widths of $1 \mathrm{~km}$. In summer, physical processes in the PRE are influenced by abundant river discharge and southwesterly prevailing winds. Complicated hydrodynamics and topography significantly affect the spatial and temporal distributions of nutrients, phytoplankton, and DO. Seasonal hypoxia has been reported in the PRE from several large-scale field observations since the 1970s (Yin et al., 2004). Several modelling studies have also been conducted to investigate hypoxia in the PRE (Guan et al., 2001a, b; Luo et al., 2008). Unlike the northern Gulf of Mexico, hypoxia in the PRE is intermittent and confined to a small scale (Rabouille et al., 2008), although nitrogen loadings in the PRE are close to those in the Mississippi River (Hu and Li, 2009). Previous studies suggested that high SOD dominated the DO depletion at the bottom waters and was responsible for the occurrence of bottom hypoxia in the PRE (Yin et al., 2004; Zhang and Li, 2010). However, spatial distributions of SOD and hypoxia were inconsistent and there was a location shift between the hypoxic zone and high SOD areas (Zhang and Li, 2010). No further discussion has been provided for this problem in those studies. According to our study (see details in the following sections), this location shift is ascribed to the modulation of the effects of the source and sink processes on DO due to physical transport. Specifically, in addition to the local source and sink processes, DO concentrations in local waters can also be influenced by the source and sink processes occurring in adjacent waters, which produce or consume DO in adjacent waters and then affect the DO fluxes transported from adjacent to local waters. This process demonstrates the spatial connection of each source and sink process occurring in different locations and is of great importance to the DO dynamics in a shallow riverdominated system, as in the PRE. In the traditional mass balance analysis of DO, the contribution of the adjacent source and sink processes (CAS) is included in the DO transport fluxes but its impact on hypoxia is not explicitly revealed.

The main objectives of this study are (1) to investigate the characteristics of hypoxia in the PRE, including the spatial distribution, intensity, and duration, and (2) to propose a new method (physical modulation method) to depict the modulation of the effects of the source and sink processes on DO due to physical transport and explore the mechanisms controlling the DO balance as well as the hypoxia in the PRE. The paper is organized as follows. In Sect. 2, we describe the physical and water quality models used in this study as well as the theory and methodology of the proposed physical modulation method. In Sect. 3, we present the validation of our models and the physical modulation method. Section 4 provides the results and discussion. Section 5 presents the main conclusions.

\section{Methods}

\subsection{Physical model}

In order to properly account for the interactive impacts of riverine, estuarine, and shelf-sea processes on hydrodynamics, we use a one-dimensional (1-D) and a three-dimensional (3-D) coupled physical model ( $\mathrm{Hu}$ and $\mathrm{Li}, 2009$; $\mathrm{Hu}$ et al., 2011) that integrate the Pearl River network, the PRE, and adjacent coastal waters into an overall modelling system. Specifically, the 1-D river network model is dynamically coupled with the 3-D coastal model for the PRE using an 

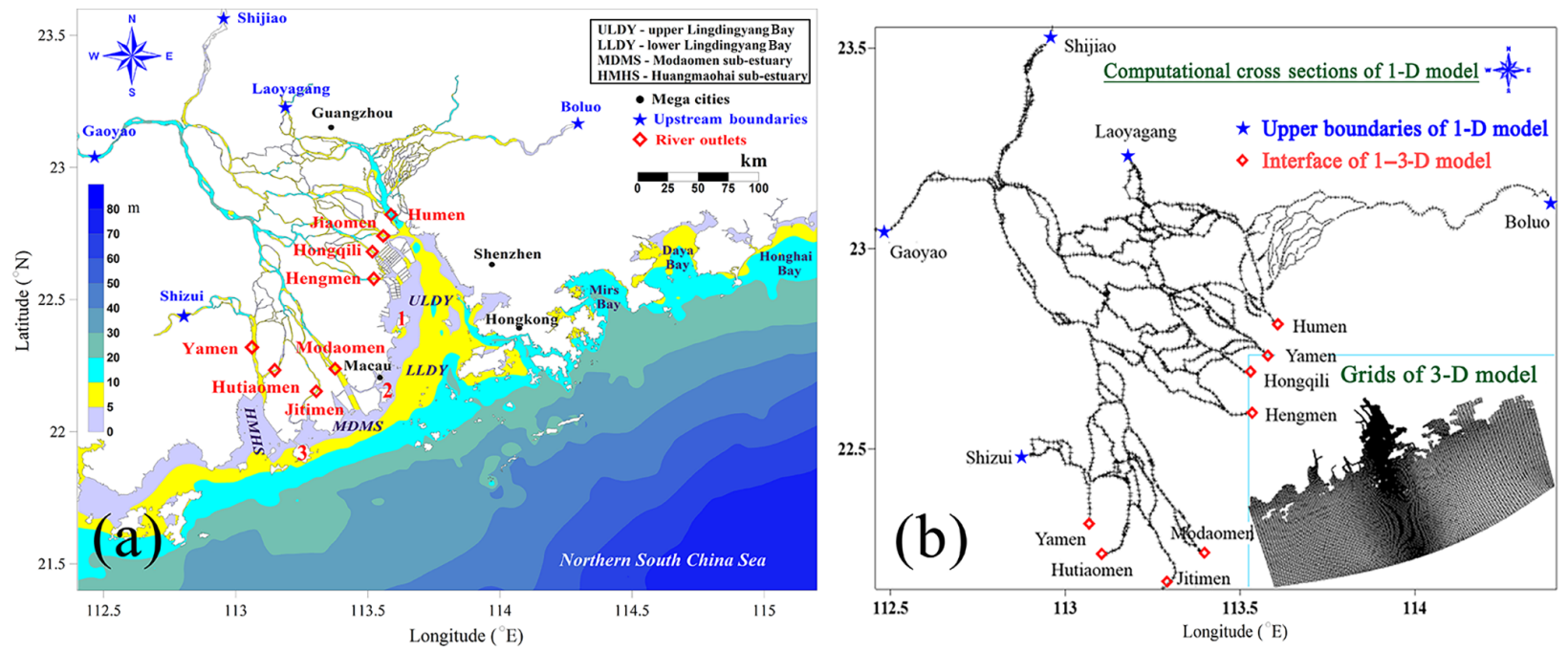

Figure 1. Maps showing (a) the Pearl River Delta with the Pearl River network and the Pearl River estuary (PRE) and (b) computational cross sections for the 1-D model and model grids for the 3-D model. The red numbers in (a) represent islands which are not marked on the map: 1 - Qi'ao island; 2 - Hengqin Island; 3 - Gaolan Island.

explicit coupling approach. The eight river outlets (Fig. 1a) serve as the coupling interface between the 1-D and the 3-D model domains. These two models run in parallel and their model quantities are exchanged across the coupling interface during runtime. At each time step, the 3-D model utilizes the simulated discharge obtained from the 1-D model as the river boundary forcing and the 3-D model sends simulated water levels to the 1-D model as the downstream boundary forcing for the next time step. A detailed description of the methodology and implementation of the coupled model can be found in $\mathrm{Hu}$ and $\mathrm{Li} \mathrm{(2009)}$.

The 1-D model uses a Preissmann implicit scheme and an iterative approach to solve the Saint-Venant equations of mass and momentum conservation. A salinity transport module is also incorporated in the model. For details on the 1-D model and its governing equations, see $\mathrm{Hu}$ and $\mathrm{Li}$ (2009). The 1-D model simulates 299 major branches of the river network with 1726 computational cross sections and 189 nodes (Fig. 1b). For the upstream boundaries, the real-time river discharge or water levels with zero salinity are specified at Shizui, Gaoyao, Shijiao, Laoyagang, and Boluo (see Fig. 1a for their locations). The initial conditions of water level and salinity are set to zero. The time step is $5 \mathrm{~s}$ for the 1-D hydrodynamic model.

The 3-D model used in this study is the Estuaries and Coastal Ocean Model with Sediment Module (ECOMSED; HydroQual, 2002, extensively used in estuaries). The model solves the Navier-Stokes equations with hydrostatic and Boussinesq approximations. A Smagorinsky-type formula is applied to parameterize horizontal mixing and the MellorYamada level 2.5 turbulent closure model is applied to calculate vertical viscosity and diffusivity (Mellor and Yamada, 1982). Details on the ECOMSED and its governing equa- tions can be found in HydroQual (2002). The 3-D model has $183 \times 186$ horizontal grids with resolutions ranging from 400-500 m inside the estuary to 3-4 km near the open boundary (Fig. 1b). Vertically, there are $16 \sigma$ levels with refined resolutions at the surface and bottom layers. At the open boundaries, tide forcing is prescribed using water levels derived from the Oregon State University Tidal Data Inversion Software (OTIS), with the uniform salinity and temperature boundary conditions based on the observed data from Wanshan Island (Hu and Li, 2009). Atmospheric forcing is interpolated into our model grid using wind, air pressure, and net solar radiation obtained from the ERA-Interim (ECMWF ERA-Interim reanalysis, http://www.ecmwf.int/en/research/ climate-reanalysis/era-interim). The spatial resolution of the ERA-Interim data is $0.125^{\circ} \times 0.125^{\circ}$ and the temporal resolution is $6 \mathrm{~h}$. The initial conditions of the water level and salinity are set to zero. The time steps are 5 and $30 \mathrm{~s}$ for the external mode and internal mode in the ECOMSED, respectively.

The 1-D and 3-D coupled physical model was first implemented in November and December 2005 to reach steady state and then continuously run from 1 January 2006 to 31 December 2006. The results of the runs for July and August 2006 were used for the analysis of summer hypoxia in the PRE.

\subsection{Water quality model}

The water quality model used in this study is the Row Column Aesop (RCA) developed by HydroQual (2004). In the water column, RCA simulates five interactive systems including the carbon cycle, nitrogen cycle, phosphorus cycle, silicon cycle, and DO balance (Fig. 2a). In addition, a sedi- 
(a)

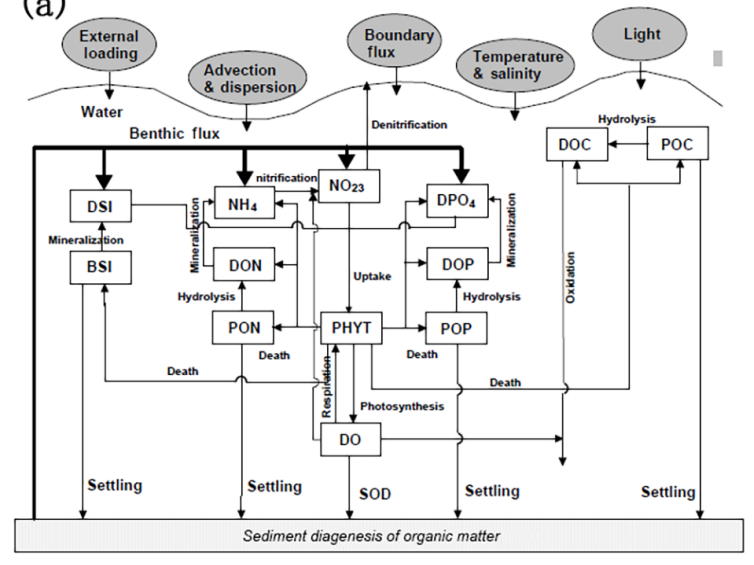

(b)

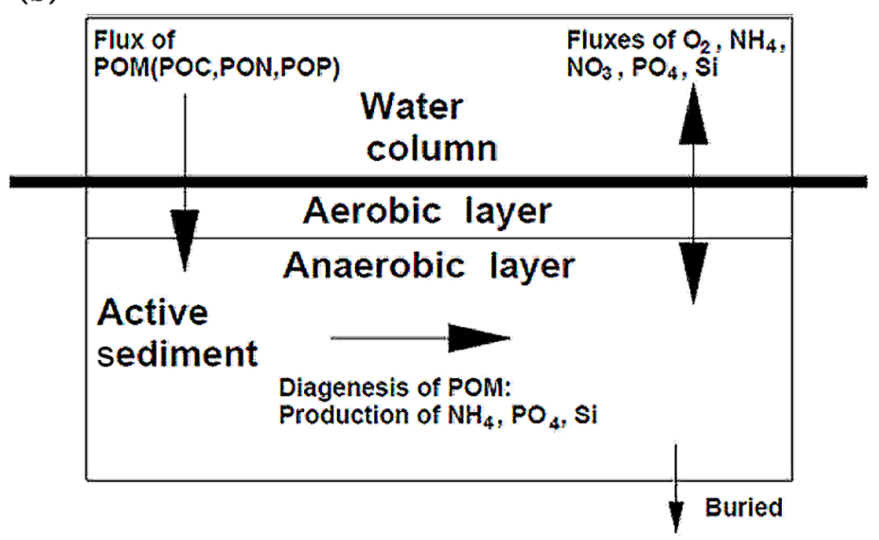

Figure 2. A conceptual framework for (a) RCA model and (b) sediment flux model (revised from Di Toro, 2001): dissolved oxygen (DO); phytoplankton (PHYT); particulate organic carbon (POC); dissolved organic carbon (DOC); ammonia nitrogen $\left(\mathrm{NH}_{4}\right)$; nitrite and nitrate nitrogen $\left(\mathrm{NO}_{23}\right)$; particulate organic nitrogen $(\mathrm{PON})$; dissolved organic nitrogen $(\mathrm{DON})$; dissolved inorganic phosphorus $(\mathrm{DPO} 4)$; particulate organic phosphorus (POP); dissolved organic phosphorus (DOP); dissolved silica (DSi); biogenic silica (BSi); sediment oxygen demand (SOD).

ment flux module is incorporated into RCA to simulate the depositional flux of particulate organic matter (including particulate organic nitrogen, particulate organic phosphorus, and particulate organic carbon), diagenesis processes in the sediment converting particulate organic matter to dissolved matters, and the transportation of dissolved matters from the sediment to the overlying water (Fig. 2b). Interactions between the water column and the sediment can be simulated internally by RCA. At each time step, the water quality module passes the calculated depositional fluxes of particulate organic matters to the sediment flux module, which in return sends the simulated SOD and nutrient fluxes to the water quality module as its bottom boundary conditions.

In the summer, the suspended sediments concentrations are high in the PRE and significantly limit the growth of phytoplankton by reducing the light penetration through the water column. The shading effects of suspended sediments are considered in RCA as follows (Di Toro, 1978):

$K_{\mathrm{e}}=0.052 N+0.174 D+0.031 P$,

where $K_{\mathrm{e}}$ represents the light extinction coefficient ( $1 \mathrm{~m}^{-1}$; Table 1$), N$ represents the sediment concentrations $\left(\mathrm{mg} \mathrm{L}^{-1}\right), D$ represents the concentrations of particulate organic matters $\left(\mathrm{mg} \mathrm{L}^{-1}\right)$, and $P$ represents the concentrations of chlorophyll $\alpha\left(\mu \mathrm{g} \mathrm{L}^{-1}\right)$. The sediment concentrations are simulated by a sediment transport module incorporated into ECOMSED (HydroQual, 2002; Hu and Li, 2009).

The equation for each water quality variable is given as

$$
\begin{aligned}
\frac{\partial C}{\partial t} & =\frac{\partial}{\partial x}\left(E_{x} \frac{\partial C}{\partial x}\right)+\frac{\partial}{\partial y}\left(E_{y} \frac{\partial C}{\partial y}\right)+\frac{\partial}{\partial z}\left(E_{z} \frac{\partial C}{\partial z}\right) \\
& -u \frac{\partial C}{\partial x}-v \frac{\partial C}{\partial y}-w \frac{\partial C}{\partial z}+S-W
\end{aligned}
$$

where $C$ represents the concentrations of each water quality variable; $x, y$, and $z$ represent the two horizontal coordinates and the vertical coordinate; $u, v$, and $w$ represent the corresponding velocity components in the $x, y$, and $z$ coordinates, respectively; $E_{x}, E_{y}$, and $E_{z}$ represent the dispersion coefficients; $S$ represents the sources and sinks for water quality variables; and $W$ represents the external inputs of nutrients and oxygen-demanding materials which originate from municipal and industrial discharges, river discharges, and atmospheric deposition.

The source processes for DO include re-aeration at the airsea interface and photosynthesis, while the sink processes for DO include nitrification of ammonia, oxidation of dissolved organic matter and dissolved sulfide, respiration by phytoplankton, and SOD at the water-sediment interface. Here, we combine nitrification, oxidation, and respiration into a single process called the water column respiration (WCR) to represent the total DO depletion in the water column. The equation describing the kinetic processes of DO is given as

$$
\begin{aligned}
S_{\mathrm{DO}} & =k_{a} \theta_{a}^{T-20}\left(\mathrm{DO}_{\mathrm{sat}}-\mathrm{DO}\right) \\
& +\alpha_{\mathrm{OC}} \cdot \alpha_{\mathrm{NH}_{4}} \cdot G_{\mathrm{P}} \cdot P_{c}+\left(\alpha_{\mathrm{NO}_{23 \mathrm{c}}}\right) \cdot\left(1-\alpha_{\mathrm{NH}_{4}}\right) \cdot G_{\mathrm{P}} \cdot P_{c} \\
& -2 \cdot \alpha_{\mathrm{ON}} \cdot k_{14,15} \theta_{14,15}^{T-20} \cdot \mathrm{NH}_{4} \cdot \frac{\mathrm{DO}}{K_{\mathrm{nitri}}+\mathrm{DO}} \\
& -\alpha_{\mathrm{OC}} \cdot\left[k_{20,0} \theta_{20,0}^{T-20} \cdot \mathrm{RDOC}+k_{21,0} \theta_{21,0}^{T-20} \cdot \mathrm{LDOC}\right. \\
& \cdot \frac{\mathrm{LDOC}}{K_{\mathrm{LDOC}}+\mathrm{LDOC}}+k_{22,0} \theta_{22,0}^{T-20} \cdot \operatorname{ReDOC} \\
& \cdot \frac{\mathrm{ReDOC}}{K_{\mathrm{LDOC}}+\mathrm{ReDOC}}+k_{23,0} \theta_{23,0}^{T-20} \\
& \left.\cdot \operatorname{ExDOC} \cdot \frac{\mathrm{ExDOC}}{K_{\mathrm{LDOC}}+\mathrm{ExDOC}}\right] \cdot \frac{P_{c}}{K_{P_{c}}+P_{c}} \cdot \frac{\mathrm{DO}}{K_{\mathrm{DO}}+\mathrm{DO}}
\end{aligned}
$$


Table 1. List of state variables in the water quality model (RCA) and the physical modulation method

\begin{tabular}{|c|c|}
\hline Variables & Descriptions (unit) \\
\hline$K_{\mathrm{e}}$ & light extinction coefficient $\left(\mathrm{m}^{-1}\right)$ \\
\hline$N$ & sediment concentration $\left(\mathrm{mg} \mathrm{L}^{-1}\right)$ \\
\hline$D$ & concentration of POM $\left(\mathrm{mg} \mathrm{L}^{-1}\right)$ \\
\hline$P$ & concentration of chlorophyll $a\left(\mu \mathrm{g} \mathrm{L}^{-1}\right)$ \\
\hline DO & dissolved oxygen $\left(\mathrm{mg} \mathrm{OL}^{-1}\right)$ \\
\hline $\mathrm{DO}_{\text {sat }}$ & saturation concentration of dissolved oxygen $\left(\mathrm{mg} \mathrm{OL}^{-1}\right)$ \\
\hline $\mathrm{DO}_{\text {sed }}$ & concentration of dissolved oxygen in the sediment $\left(\mathrm{mg} \mathrm{OL}^{-1}\right)$ \\
\hline $\mathrm{O}_{2}^{*}$ & dissolved oxygen equivalents $\left(\mathrm{mg} \mathrm{OL}^{-1}\right)$ \\
\hline$P_{c}$ & phytoplankton biomass $\left(\mathrm{mg} \mathrm{C} \mathrm{L}^{-1}\right)$ \\
\hline LDOC & labile dissolved organic carbon $\left(\mathrm{mg} \mathrm{C} \mathrm{L}^{-1}\right)$ \\
\hline RDOC & refractory dissolved organic carbon $\left(\mathrm{mg} \mathrm{CL}^{-1}\right)$ \\
\hline ReDOC & reactive dissolved organic carbon $\left(\mathrm{mg} \mathrm{CL}^{-1}\right)$ \\
\hline ExDOC & algal exudate dissolved organic carbon $\left(\mathrm{mg} \mathrm{C} \mathrm{L}^{-1}\right)$ \\
\hline $\mathrm{DO}_{\mathrm{BC}}$ & changes in DO concentrations due to the effects of boundary conditions $\left(\mathrm{mg} \mathrm{OL}^{-1}\right)$ \\
\hline $\mathrm{DO}_{S}$ & changes in DO concentrations due to the effects of source and sink terms $\left(\mathrm{mg} \mathrm{OL}^{-1}\right)$ \\
\hline DORea & changes in DO concentrations due to the effects of air-sea re-aeration $\left(\mathrm{mg} \mathrm{OL} \mathrm{L}^{-1}\right)$ \\
\hline $\mathrm{DO}_{\text {Phot }}$ & changes in DO concentrations due to the effects of photosynthesis $\left(\mathrm{mg} \mathrm{OL}^{-1}\right)$ \\
\hline DOWCR & changes in DO concentrations due to the effects of WCR $\left(\mathrm{mg} \mathrm{OL}^{-1}\right)$ \\
\hline $\mathrm{DO}_{\mathrm{SOD}}$ & changes in DO concentrations due to the effects of SOD $\left(\mathrm{mg} \mathrm{OL}^{-1}\right)$ \\
\hline
\end{tabular}

$$
\begin{aligned}
& -\alpha_{\mathrm{OC}} \cdot k_{\mathrm{PR}}(T) \cdot P_{c} \\
& -k\left(\mathrm{DO}_{\mathrm{sed}}-\mathrm{DO}\right) \\
& -k_{\mathrm{O}_{2}}^{*} \theta_{\mathrm{O}_{2}^{*}}^{T-20} \cdot \mathrm{O}_{2}^{*} \cdot \frac{P_{c}}{K_{\mathrm{Pc}}+P_{c}} \cdot \frac{\mathrm{DO}}{K_{\mathrm{DO}_{\mathrm{O}_{2}^{*}}}}+\mathrm{DO},
\end{aligned}
$$

where $k_{a}$ represents the surface mass transfer coefficient $\left(\mathrm{m} \mathrm{day}^{-1}\right)$ for re-aeration; $\theta_{a}, \theta_{14,15}, \theta_{20,0}, \theta_{21,0}, \theta_{22,0}, \theta_{23,0}$, and $\theta_{\mathrm{O}_{2}}^{*}$ represent the temperature coefficients; $\mathrm{DO}_{\text {sat }}$ represents the saturation concentration of DO $\left(\mathrm{mg} \mathrm{OL}^{-1}\right) ; \alpha_{\mathrm{OC}}$ represents the oxygen-to-carbon ratio; $\alpha_{\mathrm{NH}_{4}}$ represents the preference for ammonium uptake by phytoplankton; $G_{\mathrm{P}}$ represents the specific phytoplankton growth rate $\left(\right.$ day $\left.^{-1}\right) ; P_{c}$ represents the phytoplankton biomass $\left(\mathrm{mg} \mathrm{CL}^{-1}\right) ; \alpha_{\mathrm{NO}_{23 \mathrm{c}}}$ represents the oxygen-to-carbon ratio for nitrate uptake; $\alpha_{\mathrm{ON}}$ represents the oxygen-to-nitrogen ratio; $k_{14,15}$ represents the nitrification rate at $20{ }^{\circ} \mathrm{C}\left(\right.$ day $\left.^{-1}\right) ; K_{\text {nitri }}, K_{\mathrm{DO}}$, and $K_{\mathrm{DO}_{\mathrm{O}_{2}^{*}}}$ represent the half-saturation constants for oxygen limitation $\left(\mathrm{mg} \mathrm{OL}^{-1}\right) ; k_{20,0}, k_{21,0}, k_{22,0}$, and $k_{23,0}$ represent the oxidation rates for refractory dissolved organic carbon (RDOC), labile dissolved organic carbon (LDOC), reactive dissolved organic carbon (ReDOC), and algal exudate dissolved organic carbon (ExDOC) at $20^{\circ} \mathrm{C}\left(\mathrm{day}^{-1}\right) ; K_{\mathrm{LDOC}}$ represents the Michaelis constant for LDOC $\left(\mathrm{mg} \mathrm{CL}^{-1}\right) ; K_{\mathrm{Pc}}$ represents the half-saturation constant for phytoplankton limitation $\left(\mathrm{mg} \mathrm{CL}^{-1}\right) ; k_{\mathrm{PR}}(T)$ represents the temperature corrected algal respiration rate $\left(\mathrm{day}^{-1}\right) ; k$ represents the transfer coefficient between the sediment and the overlying water; $\mathrm{DO}_{\text {sed }}$ represents the concentration of DO in the sediment $\left(\mathrm{mg} \mathrm{OL}^{-1}\right) ; k_{\mathrm{O}_{2}}^{*}$ represents the oxidation rate of dissolved sulfide.
The simulation period for the water quality model is identical to those for the physical model with a time step of $30 \mathrm{~s}$. The initial conditions for water quality variables were derived from a 61-day spin-up simulation, which was repeated three times in order to reach steady state. The river boundaries are prescribed based on the monthly observations (including $\mathrm{DO}, \mathrm{NH}_{4}, \mathrm{NO}_{2}+\mathrm{NO}_{3}$, and $\mathrm{PO}_{4}$ ) in 2006 collected by the State Oceanic Administration and reported in Liu et al. (2015). The open boundaries are specified using historical monthly observations obtained from the State Oceanic Administration and reported in Zhang and Li (2010). The nutrient loadings were provided by the Shenzhen Environmental Protection Monitoring Centre, the Environment Council of Macau Special Administrative Region, and the Environment Protection Department of the Hong Kong Special Administrative Region. The primary parameters in the water quality model are set based on HydroQual (2004) and previous modelling studies conducted in the PRE (Table 2).

\subsection{The physical modulation method}

A new method (physical modulation method) was introduced in this study to explicitly depict the modulation of the effects of source and sink processes on DO due to physical transport. This method assumes that DO concentrations can be divided into two separate parts (Eq. 4), including the simulated DO concentrations merely driven by boundary conditions $\left(\mathrm{DO}_{\mathrm{BC}}\right)$ and the ones merely driven by internal source and sink processes $\left(\mathrm{DO}_{S}\right)$.

$\mathrm{DO}=\mathrm{DO}_{\mathrm{BC}}+\mathrm{DO}_{S}$ 
Table 2. Parameters for the water quality model (RCA).

\begin{tabular}{lrrr}
\hline Parameters & Range & Value & Units \\
\hline Maximum specific growth rate of phytoplankton & $1.7-3.0^{\mathrm{a}}$ & $2.0^{\mathrm{c}}$ & day $^{-1}$ \\
Respiration rate & $0.1-0.3^{\mathrm{a}}$ & $0.1^{\mathrm{c}}$ & day $^{-1}$ \\
RDON mineralization rate & $0.008-0.01^{\mathrm{a}}$ & $0.009^{\mathrm{c}}$ & day $^{-1}$ \\
LDON mineralization rate & $0.085-0.1^{\mathrm{a}}$ & $0.09^{\mathrm{c}}$ & day $^{-1}$ \\
RPON hydrolysis rate & $0.007-0.01^{\mathrm{a}}$ & $0.008^{\mathrm{c}}$ & day $^{-1}$ \\
LPON hydrolysis rate & $0.05-0.07^{\mathrm{a}}$ & $0.06^{\mathrm{c}}$ & day $^{-1}$ \\
RDOP mineralization rate & $0.01-0.02^{\mathrm{a}}$ & $0.01^{\mathrm{c}}$ & day $^{-1}$ \\
LDOP mineralization rate & $0.1-0.2^{\mathrm{a}}$ & $0.1^{\mathrm{c}}$ & day $^{-1}$ \\
RPOP hydrolysis rate & $0.007-0.1^{\mathrm{a}}$ & $0.008^{\mathrm{c}}$ & day $^{-1}$ \\
LPOP hydrolysis rate & $0.085-0.1^{\mathrm{a}}$ & $0.09^{\mathrm{c}}$ & day $^{-1}$ \\
RDOC mineralization rate & $0.007-0.01^{\mathrm{a}}$ & $0.009^{\mathrm{c}}$ & day $^{-1}$ \\
LDOC mineralization rate & $0.1-0.15^{\mathrm{a}}$ & $0.1^{\mathrm{c}}$ & day $^{-1}$ \\
RPOC hydrolysis rate & $0.007-0.01^{\mathrm{a}}$ & $0.01^{\mathrm{c}}$ & day $^{-1}$ \\
LPOC hydrolysis rate & $0.07-0.1^{\mathrm{a}}$ & $0.08^{\mathrm{c}}$ & day $^{-1}$ \\
RPON, LPON, RPOP, LPOP, RPOC, LPOC settling rates & $0.5-1.0^{\mathrm{a}}$ & $0.5^{\mathrm{c}}$ & $\mathrm{m} \mathrm{day}^{-1}$ \\
Nitrification rate & $0.05-0.1^{\mathrm{a}}$ & $0.08^{\mathrm{c}}$ & day $^{-1}$ \\
Denitrification rate & $0.05-0.4^{\mathrm{a}}$ & $0.09^{\mathrm{c}}$ & day $^{-1}$ \\
G1 POM diagenesis rate & $0.035^{\mathrm{b}}$ & $0.035^{\mathrm{b}}$ & day $^{-1}$ \\
G2 POM diagenesis rate & $0.0018^{\mathrm{b}}$ & $0.0018^{\mathrm{b}}$ & day $^{-1}$ \\
G3 POM diagenesis rate & $0-1.0 \times 10^{-6} \mathrm{~b}$ & $1.0 \times 10^{-7 \mathrm{c}}$ & day $^{-1}$ \\
Nitrification rate in the sediment & $0.1313^{\mathrm{b}}$ & $0.1313^{\mathrm{b}}$ & $\mathrm{m} \mathrm{day}^{-1}$ \\
Denitrification rate in the aerobic layer & $0.2-1.25^{\mathrm{b}}$ & $1.25^{\mathrm{c}}$ & $\mathrm{m} \mathrm{day}^{-1}$ \\
Denitrification rate in the anaerobic layer & $0.25^{\mathrm{b}}$ & $0.25^{\mathrm{b}}$ & $\mathrm{m} \mathrm{day}^{-1}$ \\
\hline
\end{tabular}

a HydroQual (2004); ${ }^{\mathrm{b}}$ Di Toro (2001); ${ }^{\mathrm{c}}$ Zhang and Li (2010)

where $\mathrm{DO}_{\mathrm{BC}}$ and $\mathrm{DO}_{S}$ represent the changes in $\mathrm{DO}$ concentrations due to the effects of boundary conditions and the source and sink processes, respectively. Governing equations for $\mathrm{DO}, \mathrm{DO}_{\mathrm{BC}}$, and $\mathrm{DO}_{S}$ are given as

$$
\begin{aligned}
& \frac{\partial \mathrm{DO}}{\partial t}+\mathrm{ADV}(\mathrm{DO})-\mathrm{DIFF}(\mathrm{DO})=S, \\
& \frac{\partial \mathrm{DO}_{\mathrm{BC}}}{\partial t}+\mathrm{ADV}\left(\mathrm{DO}_{\mathrm{BC}}\right)-\operatorname{DIFF}\left(\mathrm{DO}_{\mathrm{BC}}\right)=0, \\
& \frac{\partial \mathrm{DO}_{S}}{\partial t}+\mathrm{ADV}\left(\mathrm{DO}_{S}\right)-\operatorname{DIFF}\left(\mathrm{DO}_{S}\right)=S,
\end{aligned}
$$

where ADV represents the process of advection $\left(u \frac{\partial}{\partial x}+v \frac{\partial}{\partial y}+\right.$ $\left.w \frac{\partial}{\partial z}\right)$; DIFF represents the process of diffusion $\left(\frac{\partial}{\partial x}\left(E_{x} \frac{\partial}{\partial x}\right)+\right.$ $\left.\frac{\partial}{\partial y}\left(E_{y} \frac{\partial}{\partial y}\right)+\frac{\partial}{\partial z}\left(E_{z} \frac{\partial}{\partial z}\right)\right) ; \pm S$ represents the source and sink terms including the re-aeration, photosynthesis, WCR, and SOD (Eq. 3). The $\mathrm{DO}_{\mathrm{S}}$ can be further divided into four different terms:

$\mathrm{DO}_{S}=\mathrm{DO}_{\text {Rea }}+\mathrm{DO}_{\text {Phot }}+\mathrm{DO}_{\mathrm{WCR}}+\mathrm{DO}_{\mathrm{SOD}}$,

where $\mathrm{DO}_{\text {Rea }}, \mathrm{DO}_{\text {Phot }}, \mathrm{DO}_{\mathrm{WCR}}$, and $\mathrm{DO}_{\mathrm{SOD}}$ represent the changes in DO concentrations due to the effects of reaeration, photosynthesis, WCR, and SOD, respectively (Table 1). These four variables can be simulated using Eq. (7) except that $S$ refers to their corresponding source and sink terms. The positive values of $\mathrm{DO}_{\text {Rea }}$ and $\mathrm{DO}_{\text {Phot }}$ indicate that re-aeration and photosynthesis are the sources of DO and thus lead to an increase in DO concentrations; in contrast, negative values of $\mathrm{DO}_{\mathrm{WCR}}$ and $\mathrm{DO}_{\mathrm{SOD}}$ indicate that the WCR and SOD are the sinks of DO and thus cause a decrease in DO concentrations. By combining Eqs. (4)-(7), the changes in $\mathrm{DO}$ can be divided into three parts:

$$
\Delta \mathrm{DO}=\Delta \mathrm{DO}_{\mathrm{BC}}+\Delta \mathrm{DO}_{S},
$$

where $\Delta t \times\left[-\mathrm{ADV}\left(\mathrm{DO}_{\mathrm{BC}}\right)+\mathrm{DIFF}\left(\mathrm{DO}_{\mathrm{BC}}\right)\right]$ represents the contributions of boundary conditions (CBC); $\Delta t \times S$ represents the contributions of local source and sink processes (CLS), which directly affect the DO concentrations in local waters; $\Delta t \times\left[-\mathrm{ADV}\left(\mathrm{DO}_{S}\right)+\mathrm{DIFF}\left(\mathrm{DO}_{S}\right)\right]$ represents the contributions of CAS, which affect the advective and diffusive DO fluxes by altering the DO concentrations in adjacent waters. The last term presents the modulation of the effects of the source and sink processes on DO due to physical transport and denotes the interactive impacts of physical and biogeochemical processes occurring in different locations. The traditional mass balance analysis of DO is not able to distinguish CBC and CAS as they are combined into the overall DO transport flux. However, with the application of the physical modulation method proposed here, these two terms can 
be separated from one another so that their respective contributions on the DO dynamics can be accurately quantified.

Additional numerical oxygen tracers were implemented in RCA to simulate five new variables associated with the physical modulation method, namely $\mathrm{DO}_{\mathrm{BC}}, \mathrm{DO}_{\mathrm{Rea}}$, DOPhot, DOWCR, and $\mathrm{DO}_{\mathrm{SOD}}$. The simulation of $\mathrm{DO}_{\mathrm{BC}}$ is forced by the same initial and boundary conditions with the DO simulation. For the simulations of $\mathrm{DO}_{\text {Rea }}, \mathrm{DO}_{\text {Phot }}, \mathrm{DO}_{\mathrm{WCR}}$, and $\mathrm{DO}_{\mathrm{SOD}}$, the initial and boundary conditions are all set to zero. Each source and sink term associated with DO is calculated at each time step using Eq. (3). The validation of the physical modulation method is presented in Sect. 3 .

\section{Model validation}

\subsection{Validations of physical and water quality models}

Datasets used for model validation include hourly water levels at eight tidal stations and cruise observations conducted during July and August 2006 (see Fig. 3a for the locations of the survey stations). The tidal stations are located at Jiaomen, Hengmen, Modaomen, Jitimen, Hutiaomen, Yamen, Zhuhai, and Wanshan islands. Cruise observations include the profiles of salinity, temperature, and DO. The Taylor diagram in Fig. 3b gives a general statistical evaluation of our physical and water quality models. Green isolines provide a measure of model performance, denoted by the centred root-meansquare difference (RMSD) normalized by observed values. The distances between the reference point of observations (red pentagram) and the points for simulated variables are proportional to the normalized RMSD. The angular coordinate shows the magnitude of the correlation with the observations and the radial coordinate represents the standard deviations of the simulated values normalized by the observed values. A perfect match between the model and the observations would have a correlation coefficient of 1 , a normalized RMSD of 0 , and a normalized standard deviation of 1 .

There is a good agreement between the simulated and observed water levels at the eight tidal stations (Fig. 4), with the normalized RMSD $<0.30$ of the standard deviation of observations, correlation coefficients $>0.95$, and the normalized standard deviations close to 1 at all stations (Fig. 3b). In general, our model successfully reproduced the realistic variations of tidal ranges and the spring-neap tidal cycles. Comparisons of the simulated salinity and temperature with the observations are shown in Figs. 5 and 6, respectively. The simulated results follow the observed spatial distributions closely. Both the model results and the observations indicate that during the summer, the PRE is mainly occupied by freshwater originated from the Pearl River network, with a significant westward spreading of the river plume along the coast, while the shelf is mostly filled with saline water. The normalized RMSDs for salinity and temperature were relatively small $(<0.60$ of the standard deviation of obser- vations) and the correlation coefficients were high $(>0.90)$ (Fig. 3b).

The comparison between the simulated and observed DO concentrations at the bottom layer is shown in Fig. 7. The observations were collected in four different monitoring cruises, each of which lasted for 3-4 days. The simulated DO concentrations averaged over the same period were adopted for comparison purposes. Our model generally reproduced the observed DO distributions and captured the observed hypoxia on the shelf off the Modaomen sub-estuary (Fig. 7c). This hypoxic zone has also been reported by previous observational (Cai et al., 2013) and modelling studies (Zhang and $\mathrm{Li}, 2010$ ). The DO concentrations are relatively low in the upper Lingdingyang Bay due to the inflow of lowoxygen water from the river outlets but they increase gradually along the estuary to $5 \mathrm{mg} \mathrm{L}^{-1}$ in the lower Lingdingyang Bay. The simulated results generally follow the observed patterns. However, the model underestimates the variations in DO concentrations, with a normalized standard deviation of $\sim 0.63$ because the model fails to reproduce the super saturation of DO observed at the surface. The correlation coefficient for DO is relatively high $(>0.60)$ and the normalized RMSD is less than 0.80 of the standard deviation of observations (Fig. 3b). To further gain an insight into the differences between the simulation results and the observations, we analyse the frequency distribution of their biases normalized by the standard deviation of observations (Fig. 3c and d). Overall, $85 \%$ of the normalized biases are within \pm 1 and the model underestimates the DO concentrations by 0.34 of the standard deviation of observations.

In order to further evaluate the model performance in terms of depicting the important kinetic processes controlling the DO dynamics, we compared the simulated re-aeration, SOD, and respiration rates with historical estimated values obtained from previous studies (Table 3 ). The respiration rate was estimated by subtracting the nitrification rate from WCR (He et al., 2014). The simulated values were comparable to the historical estimations (Table 3). The observed re-aeration rates exhibit strong spatial variability with the maximum values occurring near river outlets and decreasing sharply to negative values in the mouth of the estuary, while the maximum values of SOD occur in the middle of the estuary. Our model reasonably reproduced the observed patterns of the reaeration and SOD. We also conducted the model-data comparisons for chlorophyll $a$, particulate organic carbon (POC), and primary productivity as they are important variables associated with the respiration rate and SOD; as shown in Table 3 , the simulated values were in agreement with the observations.

The comparisons show that our models are robust to the spatial and temporal variability of hydrodynamic parameters and DO as well as relevant important biogeochemical parameters. The spatial extent of hypoxia near the Modaomen subestuary from our simulation is consistent with the previous studies as mentioned above. Nevertheless, the model-data 

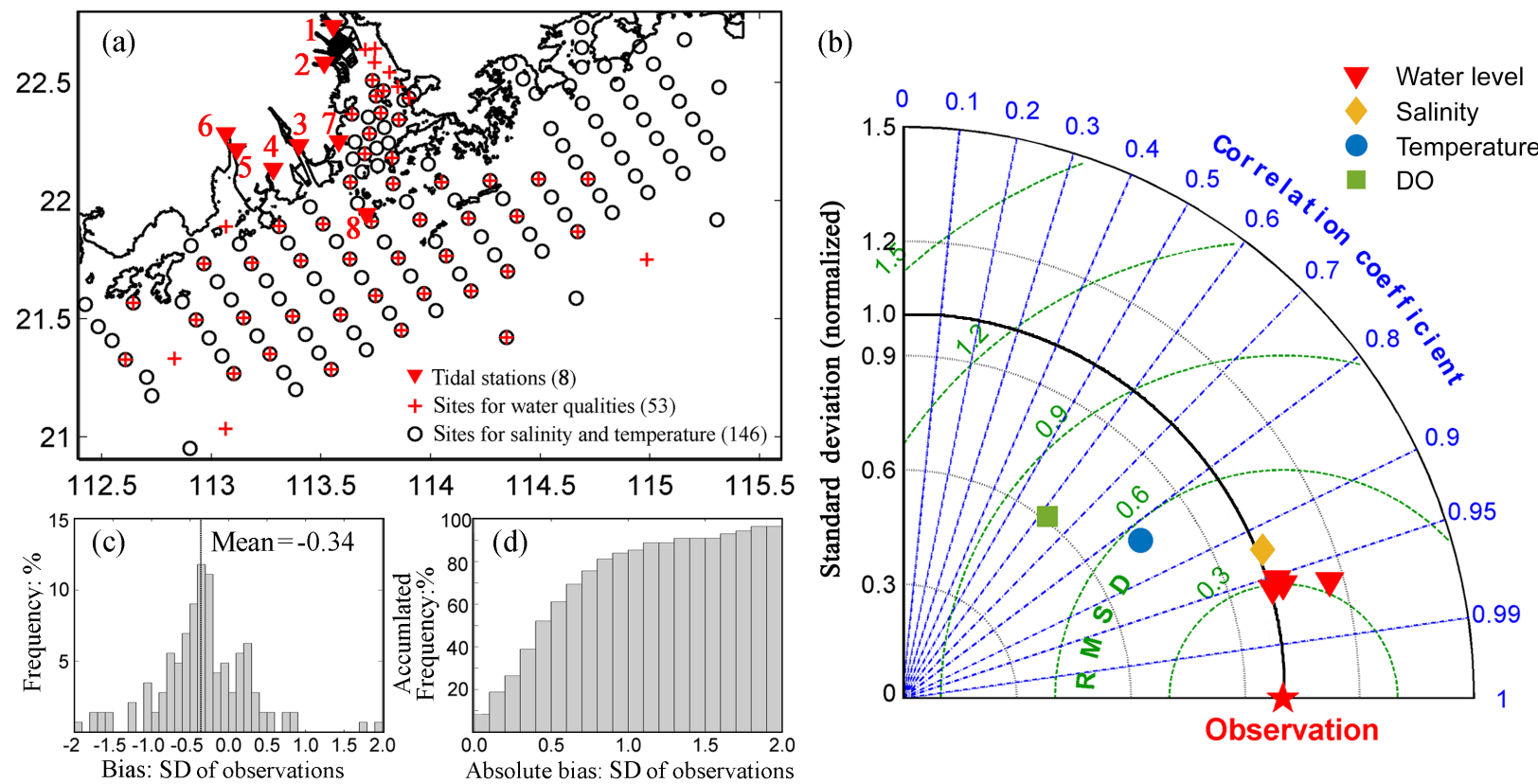

Figure 3. (a) Survey stations of water levels (red triangles), salinity and temperature (black circles), and water quality variables (red crosses) during July and August 2006. (b) Normalized Taylor diagram illustrating the model skills of simulating the water levels (red triangles), salinity (orange diamonds), temperature (blue circles), and DO (green squares). (c) Frequency and (d) accumulated frequency distribution as a function of the biases and absolute values of the biases normalized by the standard deviation of observations between the simulated and the observed DO concentrations. Note that positive values represent a model's overestimations on the DO concentrations, while negative values represent underestimations. 1 - Jiaomen; 2 - Hengmen; 3 - Modaomen; 4 - Jitimen; 5 - Hutiaomen; 6 - Yamen; 7 - Zhuhai; 8 - Wanshan Island.

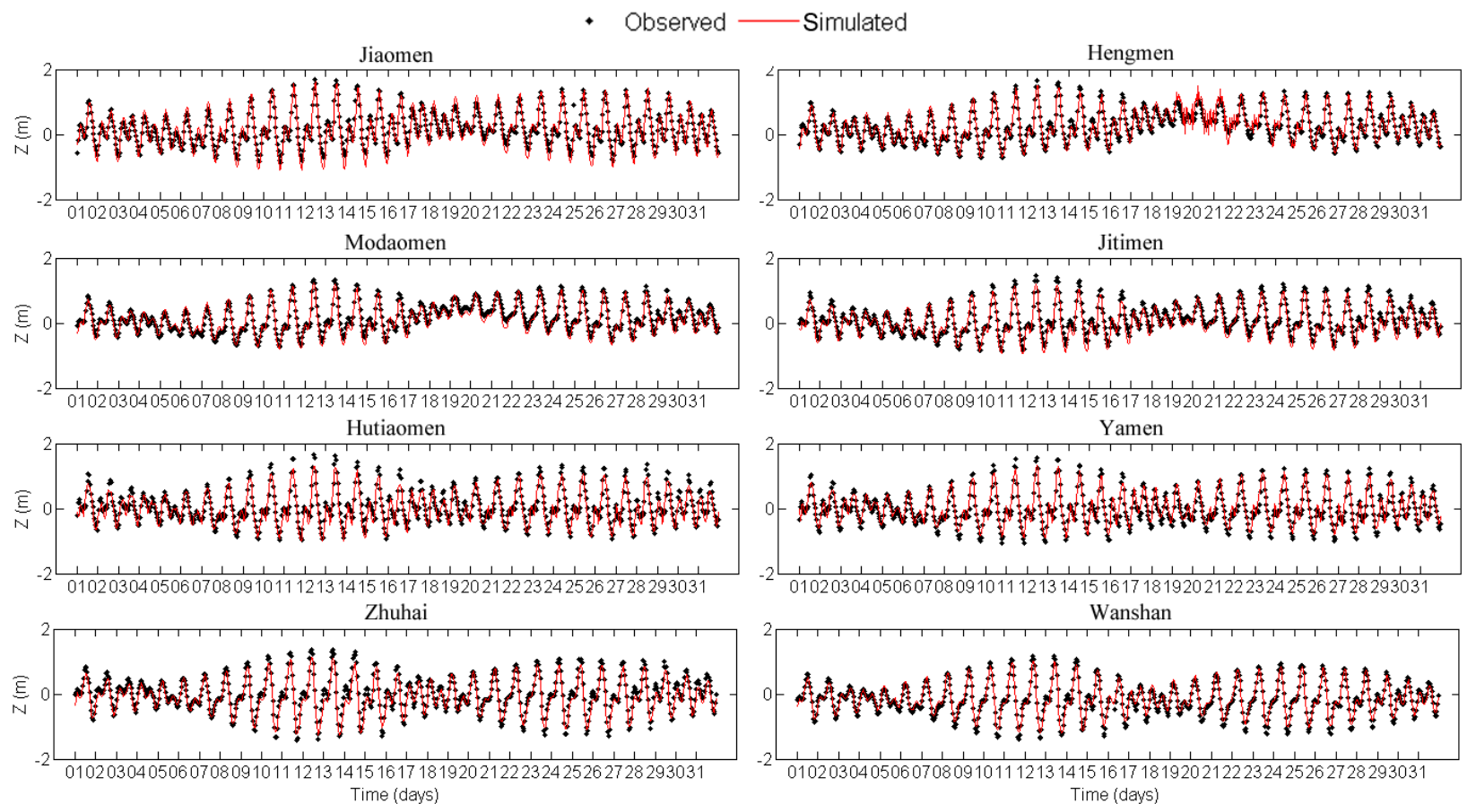

Figure 4. Comparisons of the simulated (red lines) and the observed (black dots) water levels at eight tidal stations during July 2006. Locations for the tidal stations are shown in Fig. $3 \mathrm{a}$. 

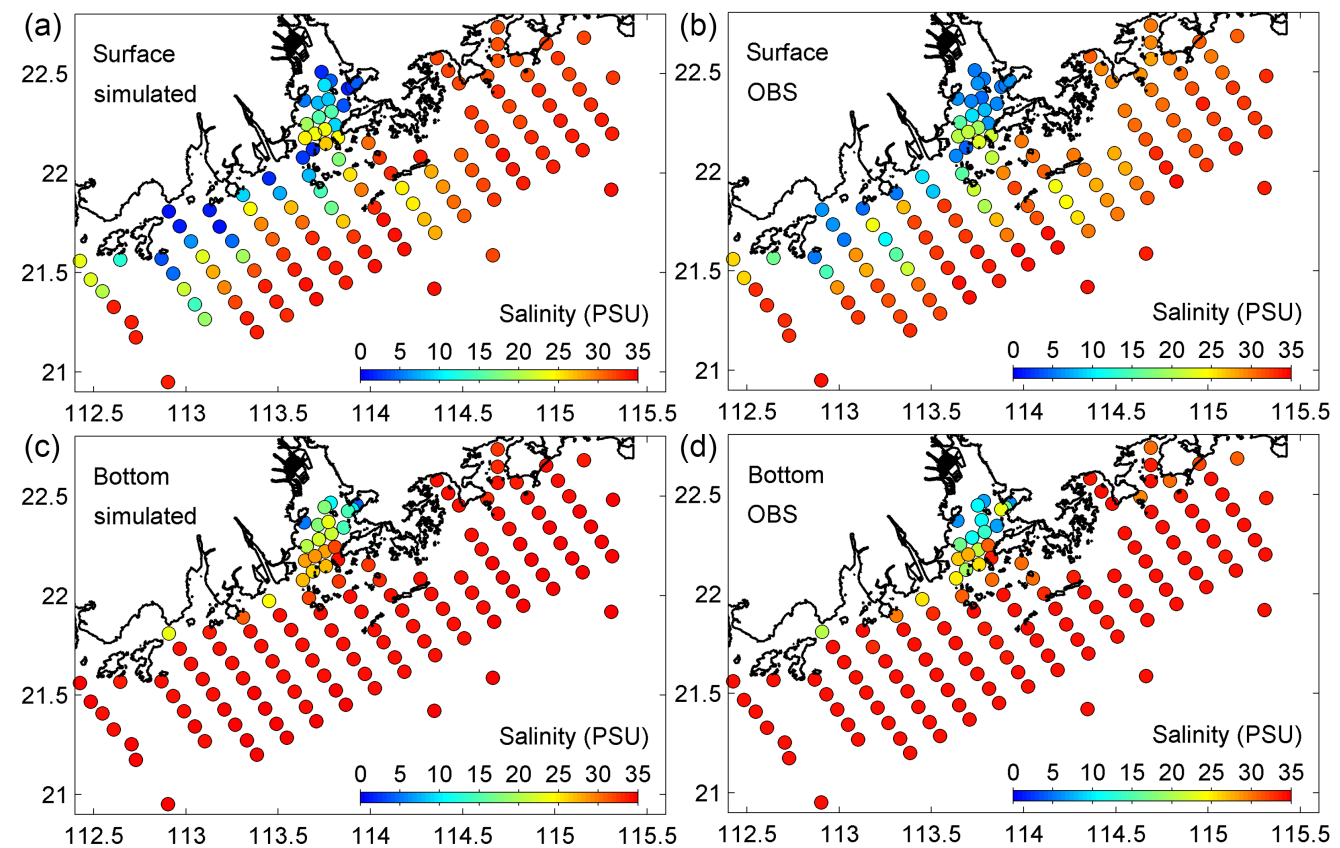

Figure 5. Comparisons of the simulated (left panels) and the observed (right panels) salinity at the surface layer (upper panels) and the bottom layer (lower panels) during July and August 2006.
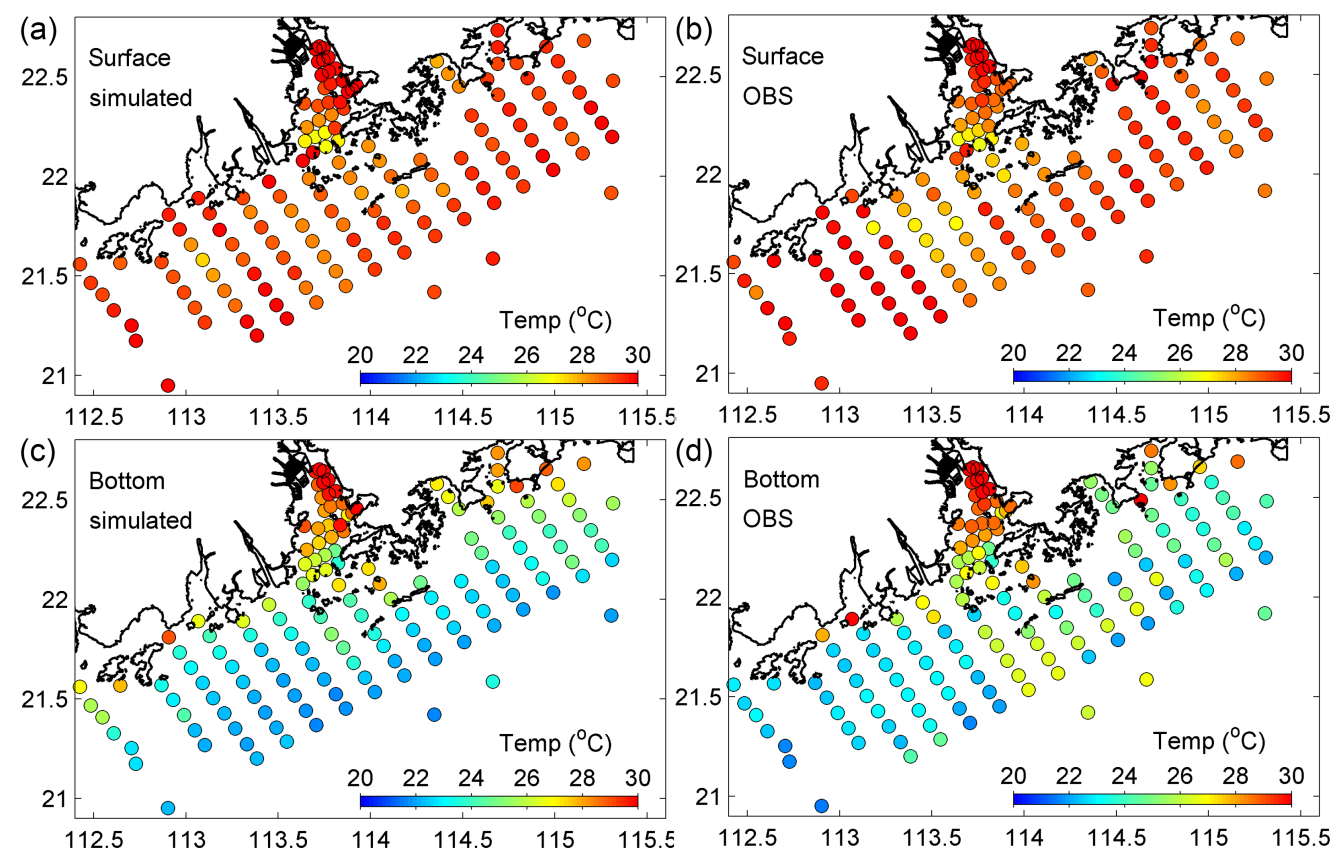

Figure 6. Comparisons of the simulated (left panels) and the observed (right panels) temperature at the surface layer (upper panels) and the bottom layer (lower panels) during July and August 2006.

comparison for hypoxia presented here is limited due to data insufficiency at the current stage. We suggest strengthening the direct observations on hypoxia and those related to the important kinetic processes affecting DO in future studies to provide a more comprehensive evaluation of the model performance. 


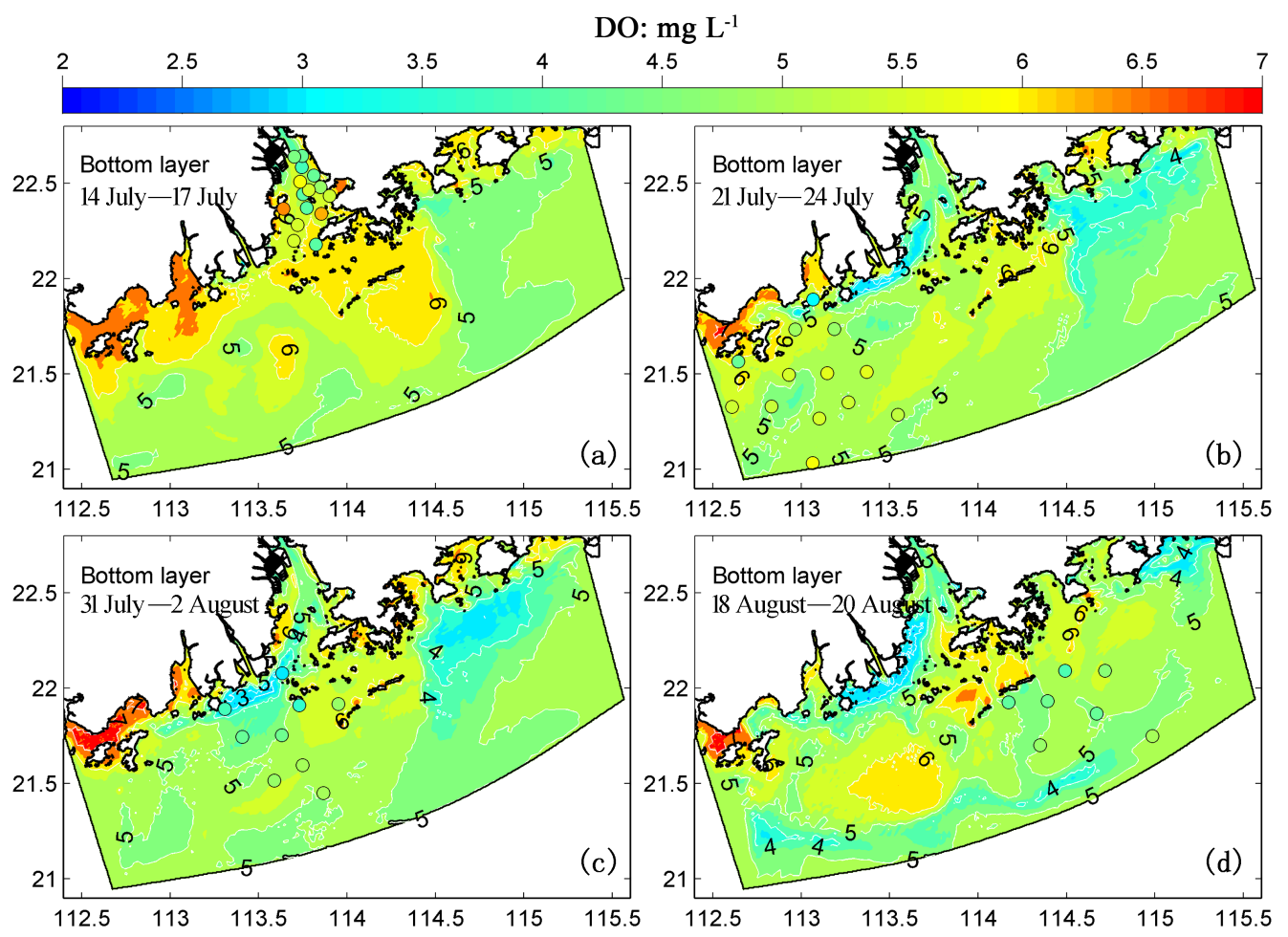

Figure 7. Comparisons of the simulated (coloured map) and the observed (coloured dots) DO concentrations at the bottom layer during July and August 2006.

Table 3. Comparisons between the simulated and historically estimated values during summer at the Lingdingyang Bay: re-aeration rate (Rea); sediment oxygen demand (SOD); respiration rate (Resp); chlorophyll $a$ (Chl $a$ ) concentrations; primary productivity (PP); particulate organic carbon (POC) concentrations. Note that positive values represent DO production rates, while negative values represent DO consumption rates.

\begin{tabular}{lrrl}
\hline & Simulated & Historically estimated & Time period \\
\hline Rea $\left(\mathrm{g} \mathrm{m}^{-2} \mathrm{day}^{-1}\right)$ & $-0.09-9.59$ & $-0.68-6.8^{\mathrm{a}}$ & Aug 2005; Aug 2008 \\
SOD $\left(\mathrm{g} \mathrm{m}^{-2} \mathrm{day}^{-1}\right)$ & -1.01 to -3.53 & -0.72 to $-3.89^{\mathrm{b}}$ & Jul 1999 \\
Resp $\left(\mathrm{mg} \mathrm{L}^{-1} \mathrm{day}^{-1}\right)$ & 0.00 to -0.27 & -0.11 to $-0.37^{\mathrm{a}}$ & Aug 2008 \\
Chl $\left(\mu \mathrm{g} \mathrm{L}^{-1}\right)$ & $1.92 \pm 1.96$ & $1.64^{\mathrm{c}}$ & Jun 2012 \\
PP $\left(\mathrm{mg} \mathrm{m}^{-2} \mathrm{day}^{-1}\right)$ & $310.8 \pm 427.5$ & $302.9^{\mathrm{c}}$ & Jun 2012 \\
POC $\left(\mathrm{mg} \mathrm{L}^{-1}\right)$ & $<0.5-3.01$ & $0.40->2.50^{\mathrm{d}}$ & Nov 2013, Feb 2014, May 2014, and Aug 2014 \\
\hline
\end{tabular}

${ }^{\text {a }}$ He et al. (2014); ${ }^{\text {b }}$ Chen et al. (2004); ${ }^{\mathrm{c}}$ Ye et al. (2015); ${ }^{\mathrm{d}}$ Guo et al. (2015)

\subsection{Validation of the physical modulation method}

Theoretically, there should be no differences in terms associated with DO dynamics between the physical modulation method and RCA if the methodology and implementation of the physical modulation method are right. Therefore, the comparisons of the July-August-averaged DO distributions simulated by these two methods are shown in Fig. 8 to assess the accuracy of the physical modulation method. Overall, DO distributions simulated by the physical modulation method were in good agreement with those simulated by RCA. At the surface layer, the physical modulation method slightly over- estimated RCA simulations in the Lingdingyang Bay and its adjacent areas, yet underestimated RCA simulations on the shelf (Fig. 8a). This is also true for the middle layer (Fig. 8b). At the bottom layer, the physical modulation method simulated DO concentrations slightly higher within the model domain (Fig. 8c). Additional numerical tests suggested that the differences in DO concentrations between the two methods were caused by the nonlinear numerical methods used in the water quality model. These nonlinear numerical methods are applied to restrain the errors brought by discretizing the linear partial differential equations. 


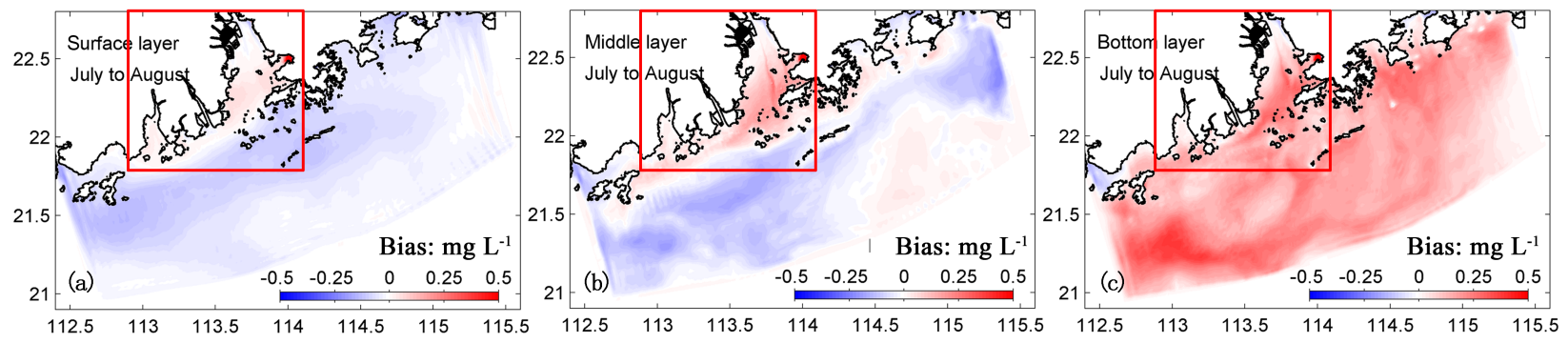

Figure 8. Spatial distributions of the biases of the simulated DO concentrations (averaged over July-August 2006) between the physical modulation method and the water quality model (RCA). Note that positive values (red) indicate that the physical modulation method overestimates the DO concentrations simulated by RCA, while negative values indicate underestimations. The red box represents the main part of the Pearl River estuary (PRE), which is the area of interest in this study.

Frequency distributions of the biases between the physical modulation method and RCA are computed over the whole model domain and for different bias bins between -1.0 and $1.0 \mathrm{mg} \mathrm{L}^{-1}$ (Fig. 9a). The layers where the bias varies between -0.1 and $0.3 \mathrm{mg} \mathrm{L}^{-1}$ occupy about $97 \%$ of the total volume in our model domain. Therefore, the DO concentration simulated by the physical modulation method is close to the DO concentration derived from RCA, whereas it is slightly overestimated by the physical modulation method. A linear regression of the spatially averaged DO concentration (averaged over the area represented by the red box in Fig. 8) further suggested that the physical modulation method reproduced the comparable temporal patterns of DO concentrations, which agreed well with the temporal pattern obtained from RCA with the regression coefficient of $R^{2}>0.99$ and the regression slope of $\sim 1: 1$ (Fig. 9b). Therefore, the acceptable differences in DO concentrations between these two methods indicated the feasibility of the physical modulation method.

Comparisons of the horizontal advective DO fluxes, vertical advective DO fluxes, and vertical diffusive DO fluxes were also conducted (Fig. 9c-e). Horizontal diffusive DO fluxes were much smaller than the other terms and hence omitted. The agreement between the DO fluxes calculated by the physical modulation method and RCA indicates that the physical modulation method is also practical for use in the diagnostic analysis of the DO balance (Fig. 9c-e). For a better assessment of the physical modulation method, some additional techniques (e.g. oxygen isotopes and artificial tracers) can be applied so that the distributions of each DO part (e.g. $\mathrm{DO}_{\mathrm{BC}}, \mathrm{DO}_{\mathrm{Rea}}, \mathrm{DO}_{\mathrm{Phot}}, \mathrm{DO}_{\mathrm{WCR}}$, and $\mathrm{DO}_{\mathrm{SOD}}$ ) can be validated directly.

\section{Results and discussion}

\subsection{Characteristics of DO distribution during summer in the PRE}

The simulated distributions for July-August-averaged DO concentration at the surface and bottom layers are shown in Fig. 10a, b. Compared with the bottom layer, DO concentrations at the surface layer were higher in most of areas except in the upper estuary (Fig. 10a) that receives a large number of low-oxygen water discharged from the river outlets. At the bottom layer, the lowest DO concentration was approximately $2 \mathrm{mg} \mathrm{L}^{-1}$ between the Jitimen and Modaomen sub-estuaries (Fig. 10b). There is a slender zone with relatively lower DO concentrations located on the shelf off the Modaomen sub-estuary, extending from Gaolan Island to Hengqin Island. The simulated July-August-averaged DO concentration remained above $3 \mathrm{mg} \mathrm{L}^{-1}$ defined as the threshold of hypoxia (Luo et al., 2008). In order to identify whether the hypoxia has occurred, we estimated the hypoxic frequency in each model grid as follows:

$P_{\mathrm{h}}=\frac{N_{\mathrm{h}}}{N_{\mathrm{T}}} \cdot 100 \%$,

where $N_{\mathrm{h}}$ is the number of hours when hypoxia occurs and $N_{\mathrm{T}}$ is the total number of hours in July and August (i.e. 1488). The hypoxic frequency in Fig. 10d shows that there is a high-frequency zone (HFZ) near the Modaomen subestuary. This HFZ zone is encompassed by $10 \%$ isoline of hypoxic frequency and resembles the low DO-concentration zone. In the HFZ, the hypoxic frequency varies from $10 \%$ to over $50 \%$ with the spatial average of $35 \%$, which means that there are, on average, 22 days during July and August with hypoxia. Furthermore, when the severe hypoxia was defined as DO $<2 \mathrm{mg} \mathrm{L}^{-1}$ (Rabalais et al., 2010), the highest hypoxic frequency in the HFZ decreased to approximately $40 \%$ and the average hypoxic frequency was $16 \%$ (Fig. 10c).

The vertical patterns of the DO concentrations along the two transects are shown in Fig. 10e, f. These two transects represent the central areas of the HFZ and their locations 

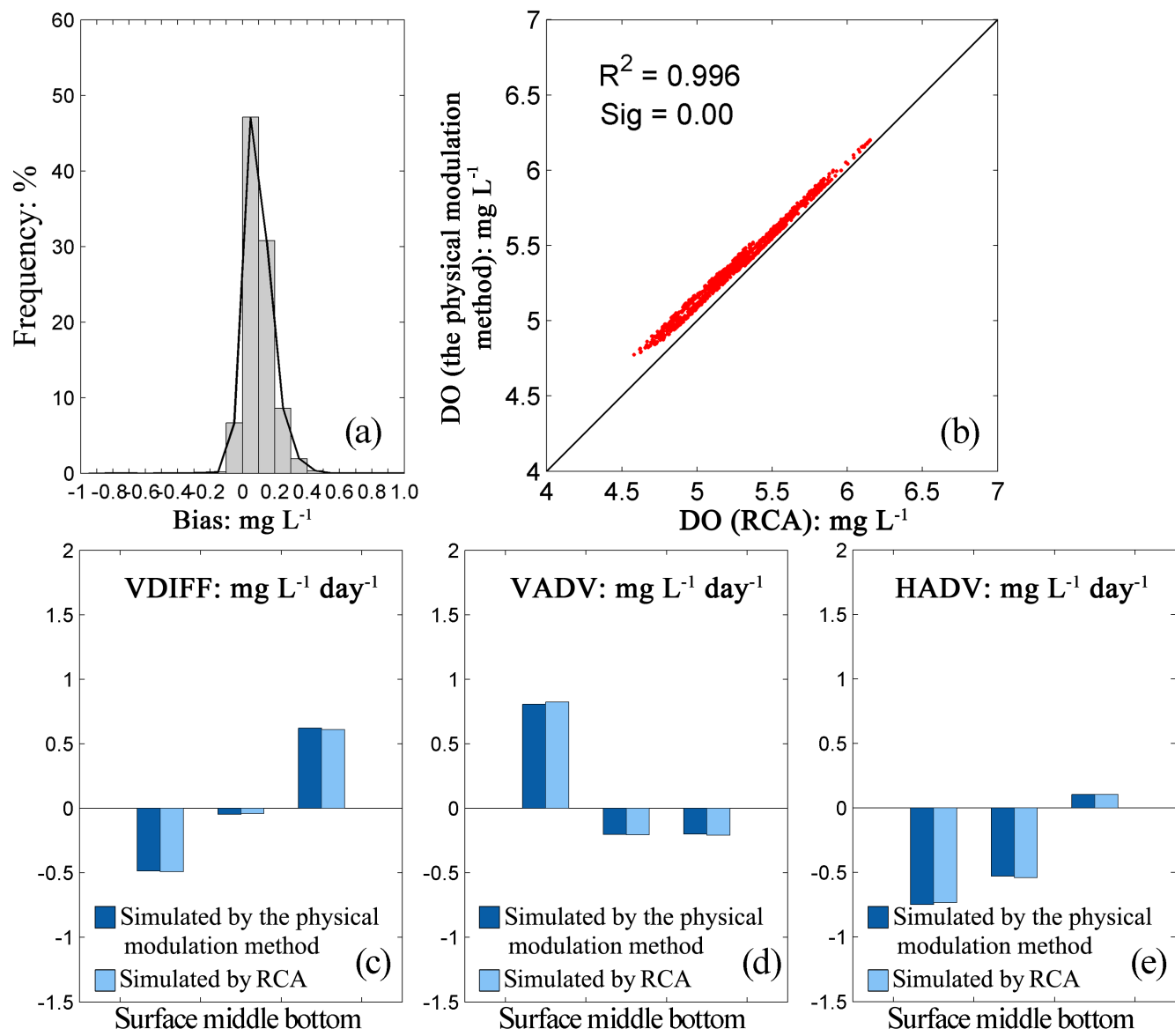

Figure 9. Comparisons for the physical modulation method and RCA: (a) frequency distribution as a function of the biases of the simulated DO concentrations; (b) the DO concentrations in the main PRE (denoted by the red box in Fig. 8); (c) the vertical DO diffusive fluxes; (d) the vertical advective DO fluxes; (e) horizontal advective DO fluxes.

are shown in Fig. 10a-d. Transect A starts from the inner Modaomen sub-estuary and extends southward, while transect B starts from Gaolan Island and ends near Hengqin Island. The parallel distribution of DO concentrations to the bottom topography can be observed in both transects during July and August (Fig. 10e, f). In transect A, surface DO concentrations range from 6 to $7 \mathrm{mg} \mathrm{L}^{-1}$ and the lowest bottom DO concentration is almost $4 \mathrm{mg} \mathrm{L}^{-1}$ (Fig. 10e). The relatively low-DO water is confined to a thin layer above the sediment. In the south end of transect A, where the depth is as much as $25 \mathrm{~m}, 7 \mathrm{mg} \mathrm{L}^{-1}$ isoline of DO concentration can penetrate into depths greater than $15 \mathrm{~m}$. The same is true for transect B (Fig. 10f), where the surface DO concentration is above $6 \mathrm{mg} \mathrm{L}^{-1}$ and the bottom DO concentration is almost $4 \mathrm{mg} \mathrm{L}^{-1}$.

Compared with the Chesapeake Bay (Hagy et al., 2004) and the northern Gulf of Mexico (Scavia et al., 2003; Rabouille et al., 2008), hypoxia in the PRE was much less severe with higher DO concentrations, a lower hypoxic frequency, and a smaller hypoxic extent. Here, we estimate the hypoxic area and hypoxic volume as follows:

hypoxic area $=\sum P_{\mathrm{h}} \cdot \Delta s$,
hypoxic volume $=\sum P_{\mathrm{h}} \cdot \Delta v$,

where $P_{\mathrm{h}}$ is the hypoxic frequency calculated using Eq. (10) and $\Delta s$ and $\Delta v$ are the area and volume of each model grid cell, respectively. Hypoxic area and hypoxic volume are the expected values which consider the temporal variability of hypoxia. If hypoxia is defined as $\mathrm{DO}<3 \mathrm{mg} \mathrm{L}^{-1}$, the expected hypoxic area and volume are 237 and $0.13 \mathrm{~km}^{3}$, respectively, much smaller than those in the northern Gulf of Mexico (13500 km²; Rabalais et al., 2007) and the Chesapeake Bay $\left(8 \mathrm{~km}^{3}\right.$; Rabalais et al., 2010).

\subsubsection{DO balance}

In order to investigate the processes that control the DO conditions, a diagnostic analysis of DO balance was conducted for the PRE (Fig. 11) and the HFZ (Fig. 12). All of the diagnostic terms are combined at each desired grid cell and 

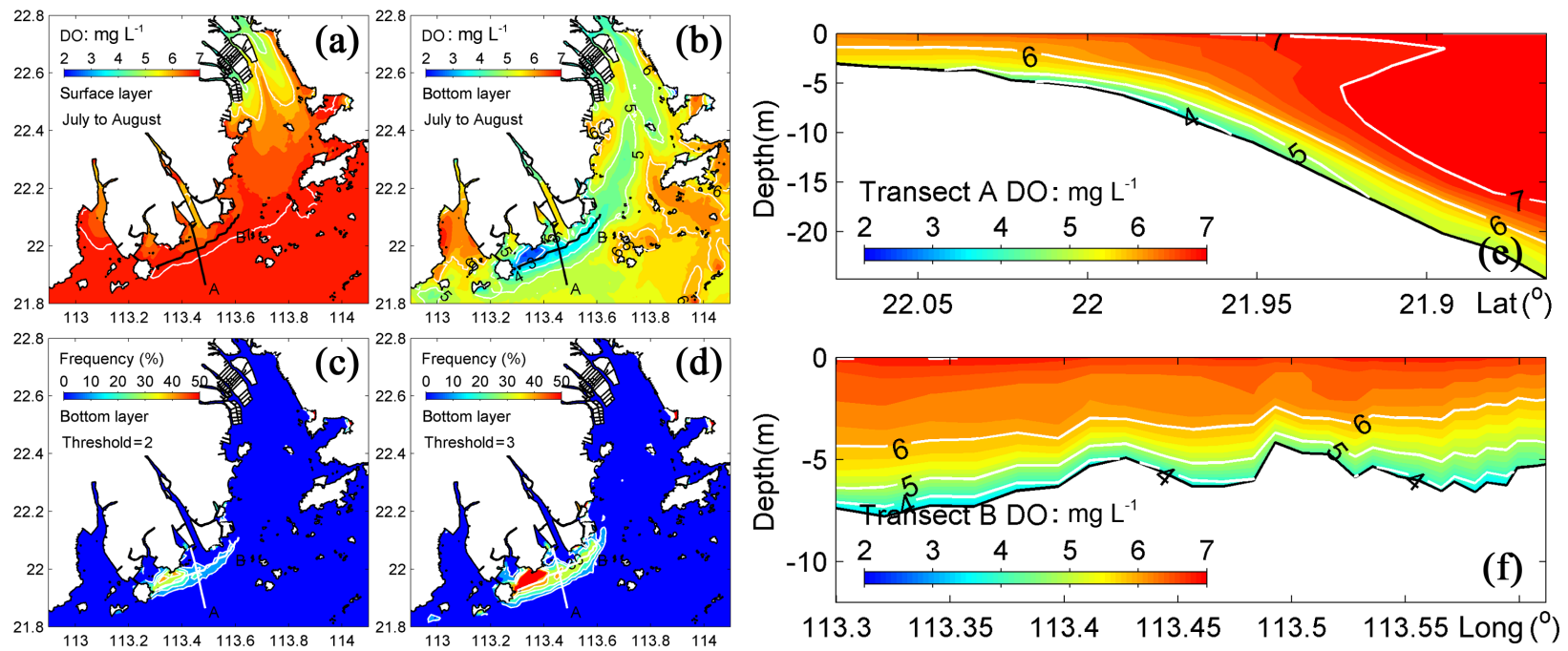

Figure 10. Spatial distributions of the monthly averaged DO concentrations at (a) the surface layer and (b) the bottom layer in the PRE. Spatial distributions of hypoxic frequency during July and August using DO thresholds of (c) $2 \mathrm{mgL}^{-1}$ and (d) $3 \mathrm{mgL}^{-1}$ for hypoxia. Vertical distributions of the DO concentrations along two transects (see their locations in a-d).

given for the upper layer, middle layer, and bottom layer. According to the survey data of the Pearl River Estuary Pollution Project (Chen et al., 2004), the pycnocline in the PRE is located at depths ranging from 1.5 to $3 \mathrm{~m}$. We, therefore, define the upper layer as the top $20 \%$ of the $10 \mathrm{~m}$ average depth in the PRE. The bottom layer is limited to $20 \%$ of the depth above the sediment where the DO concentration is relatively lower as demonstrated in Fig. 10e, f. We also estimated the contribution of each source and sink process as well as the boundary conditions to vertical advective DO fluxes (Figs. 11b and 12b), vertical diffusive DO fluxes (Figs. 11c and 12c), and horizontal advective DO fluxes (Figs. 11d and 12d). Horizontal diffusive DO fluxes are much smaller than the other terms and hence are omitted. The CBC, CAS, and CLS to the DO balance for the PRE and the HFZ are shown in Figs. 11e and 12e, respectively.

\subsubsection{PRE}

At the upper layer of the PRE, there is a DO influx of 9051 tonnes day ${ }^{-1}$ induced by re-aeration, which causes an increase in July-August-averaged DO concentrations by $0.55 \mathrm{mg} \mathrm{L}^{-1}$ day $^{-1}$ (Fig. 11a). This reoxygenation will enhance the DO vertical gradient and supplement the DO at the middle and bottom layers by vertical diffusion. According to Fig. $11 \mathrm{c}, 89 \%\left(0.48 \mathrm{mg} \mathrm{L}^{-1} \mathrm{day}^{-1}\right)$ of oxygen entering the upper layer via re-aeration will be transported to the middle layer by vertical diffusion and eventually $28 \%$ $\left(0.15 \mathrm{mg} \mathrm{L}^{-1}\right.$ day $\left.^{-1}\right)$ will reach the bottom layer (Fig. 11c). Figure 11c also shows that re-aeration is a major contributor (accounts for $99 \%$ ) to vertical diffusive DO fluxes. Another important source of DO is photosynthesis. As shown in Fig. 11c, the vertical diffusive flux of DOPhot (changes in DO concentrations due to the effects of photosynthesis; Table 1) is much smaller than that of $\mathrm{DO}_{\text {Rea }}$ (changes in $\mathrm{DO}$ concentrations due to the effects of re-aeration). This indicates that the DO gradient driven by photosynthesis is much smaller than that driven by re-aeration since the diffusion coefficients are the same. The surface DOPhot rarely reaches the middle and bottom layers through vertical diffusion (Fig. 11c) but can be transported by horizontal and vertical advection (Fig. 11b, d). Approximately $0.56 \mathrm{mg} \mathrm{L}^{-1} \mathrm{day}^{-1}$ of DOPhot is transported off the upper layer of the PRE while at the same time vertical advection brings about $0.35 \mathrm{mg} \mathrm{L}^{-1} \mathrm{day}^{-1}$ of $\mathrm{DO}_{\text {Phot }}$ from the middle layer and 2 and 1.2 times the photosynthesis rate at the upper layer (Fig. 11b, d). The $\mathrm{DO}_{\mathrm{BC}}$ (changes in DO concentrations due to the effects of the boundary conditions) and $\mathrm{DO}_{\mathrm{WCR}}$ (changes in DO concentrations due to the effects of WCR) are also transported mainly by horizontal and vertical advection (Fig. 11b, d). Moreover, SOD can exert significant negative effects on DO concentrations in the upper layer (Fig. 11b) by decreasing DO concentrations and thereby preventing the upward vertical advective DO fluxes from reaching the upper layer. In general, CAS and CLS are the most important factors controlling the DO balance (Fig. 11e). Although the boundary conditions can affect DO concentrations at the upper layer, the negative horizontal advective $\mathrm{DO}_{\mathrm{BC}}$ fluxes are close to positive vertical advective $\mathrm{DO}_{\mathrm{BC}}$ fluxes; therefore, these two processes compensate for each other (Fig. 11e).

At the middle layer, horizontal and vertical advections are the main processes controlling the DO dynamics (Fig. 11a). As the DO content transported from the middle layer to the upper layer exceeds the content transported to the middle layer from the bottom layer, the overall performance of vertical advection leads to a decrease in DO concentrations. In 

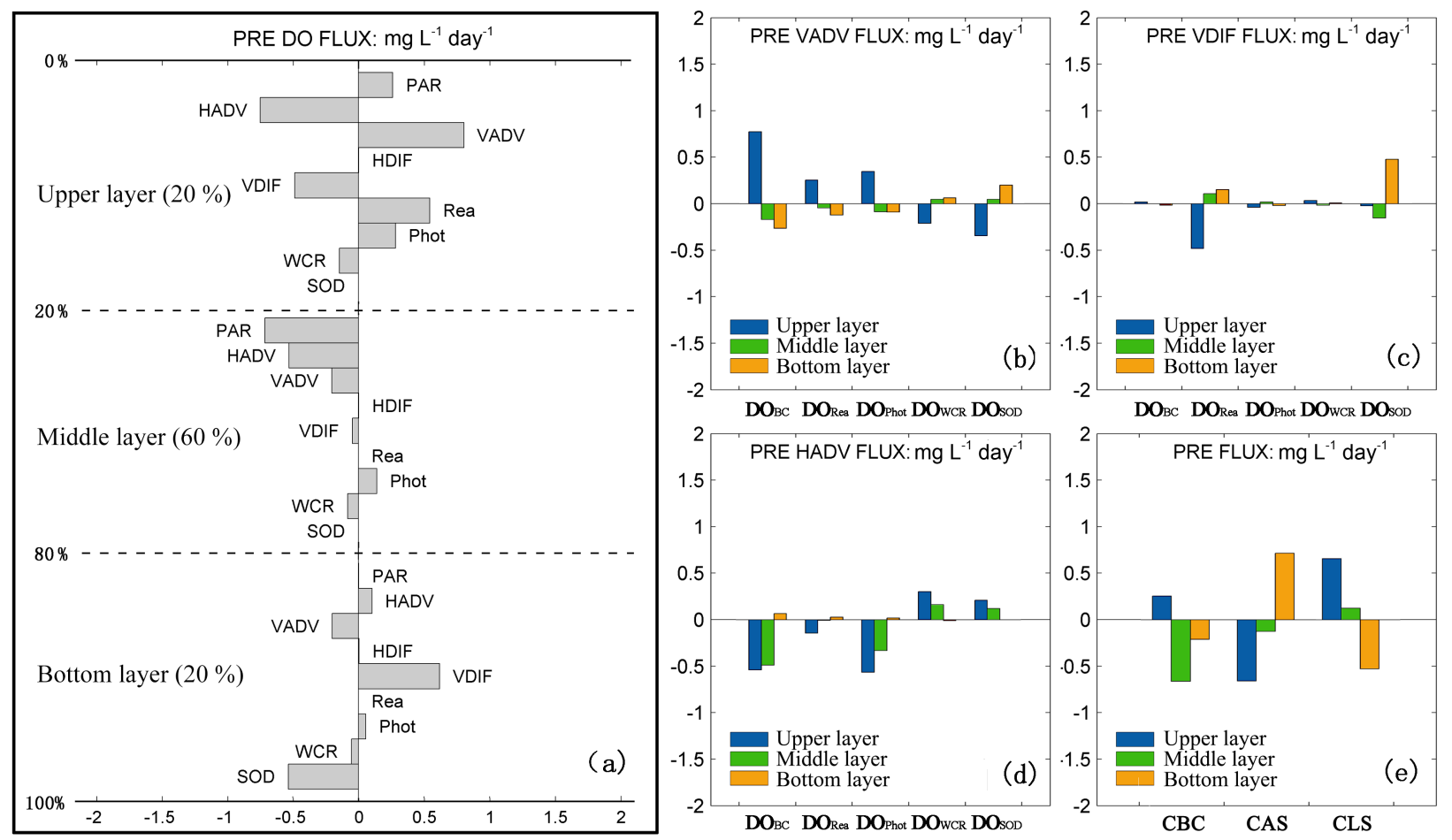

Figure 11. (a) The simulated DO mass balance (averaged over July-August 2006) for the PRE. All the diagnostic terms are given for the upper layer above the $20 \%$ of depth, for the middle layer, and for the bottom layer, which covers $20 \%$ of depth over the sediment. Contributions of each source and sink process as well as boundary conditions to (b) the vertical advective DO fluxes, (c) the vertical diffusive DO fluxes, and (d) the horizontal advective DO fluxes. (e) Contributions of boundary conditions (CBC), adjacent source and sink terms (CAS), and local source and sink terms (CLS) to the DO balance. Abbreviation PAR represents localized partial derivatives of DO; SOD and $\mathrm{DO}_{\mathrm{SOD}}$ represent the sediment oxygen demand and the changes of DO concentrations due to the effects of sediment oxygen demand, respectively; WCR and $\mathrm{DO}_{\mathrm{WCR}}$ represent the water column respiration and the changes of DO concentrations due to the effects of water column respiration, respectively; Phot and $\mathrm{DO}_{\mathrm{Phot}}$ represent the photosynthesis and the changes of DO concentrations due to the effects of photosynthesis, respectively; Rea and $\mathrm{DO}_{\mathrm{Rea}}$ represent the re-aeration and the changes of DO concentrations due to the effects of re-aeration, respectively; $\mathrm{DO}_{\mathrm{BC}}$ represents the changes of DO concentrations due to the effects of boundary conditions; VADV represents the vertical advection of DO; HADV represents the horizontal advection of DO; VDIFF represents the vertical diffusion of DO; and HDIFF represents the horizontal diffusion of DO.

addition, both the horizontal and vertical advection are dominated by the contribution of boundary conditions (Fig. 11b, d), indicating that the DO balance at the middle layer is mainly controlled by CBC (Fig. 11e).

As light becomes weak at the bottom layer, the growth of phytoplankton is limited along the shallow coastal areas. As a result, photosynthesis and WCR play trivial roles in affecting the DO balance; thus, SOD becomes a major sink for $\mathrm{DO}$ at the bottom layer. This is in contrast to the situation in the Chesapeake Bay ( $\mathrm{Li}$ et al., 2015). The discrepancies in the dominant role of SOD responsible for the total DO depletion at the bottom layer result from the differences in geometry. The Chesapeake Bay has a relatively deep channel, where SOD ranges from 0.86 to $3.2 \mathrm{~g} \mathrm{~m}^{-2}$ day $^{-1}$ and accounts for $16 \%$ of total DO depletion at the bottom layer (Boynton and Kemp, 1985). However, the PRE is characterized by the shallow banks with depths $<5 \mathrm{~m}$ where SOD ranges from 0.49 to $3.5 \mathrm{~g} \mathrm{~m}^{-2} \mathrm{day}^{-1}$. Therefore, SOD domi- nates the total DO depletion at the bottom layer with a consumption rate of $0.53 \mathrm{mg} \mathrm{L}^{-1} \mathrm{day}^{-1}$ (Fig. 11a). Furthermore, this deoxygenation results in a strong vertical DO gradient between the middle and bottom layers and thereby facilitates the downward vertical diffusion. Figure 11c shows that SOD is a major cause of vertical diffusion between the middle and bottom layers followed by re-aeration, which contribute 79 and $25 \%$ of vertical diffusive DO fluxes, respectively. Therefore, re-aeration can also have significant effects on DO concentrations at the bottom layer. Vertical advection is a major mechanism by which SOD can affect the middle layer and especially the upper layer, while vertical diffusion is a mechanism by which SOD can only affect a thin layer above the sediment (Fig. 11b, c). Figure 11a shows that the horizontal advective $\mathrm{DO}_{\mathrm{BC}}$ fluxes are close to vertical advective $\mathrm{DO}_{\mathrm{BC}}$ fluxes and these two processes compensate for each other. As a result, the DO balance at the bottom layer is mainly controlled by CAS and CLS (Fig. 11e). 

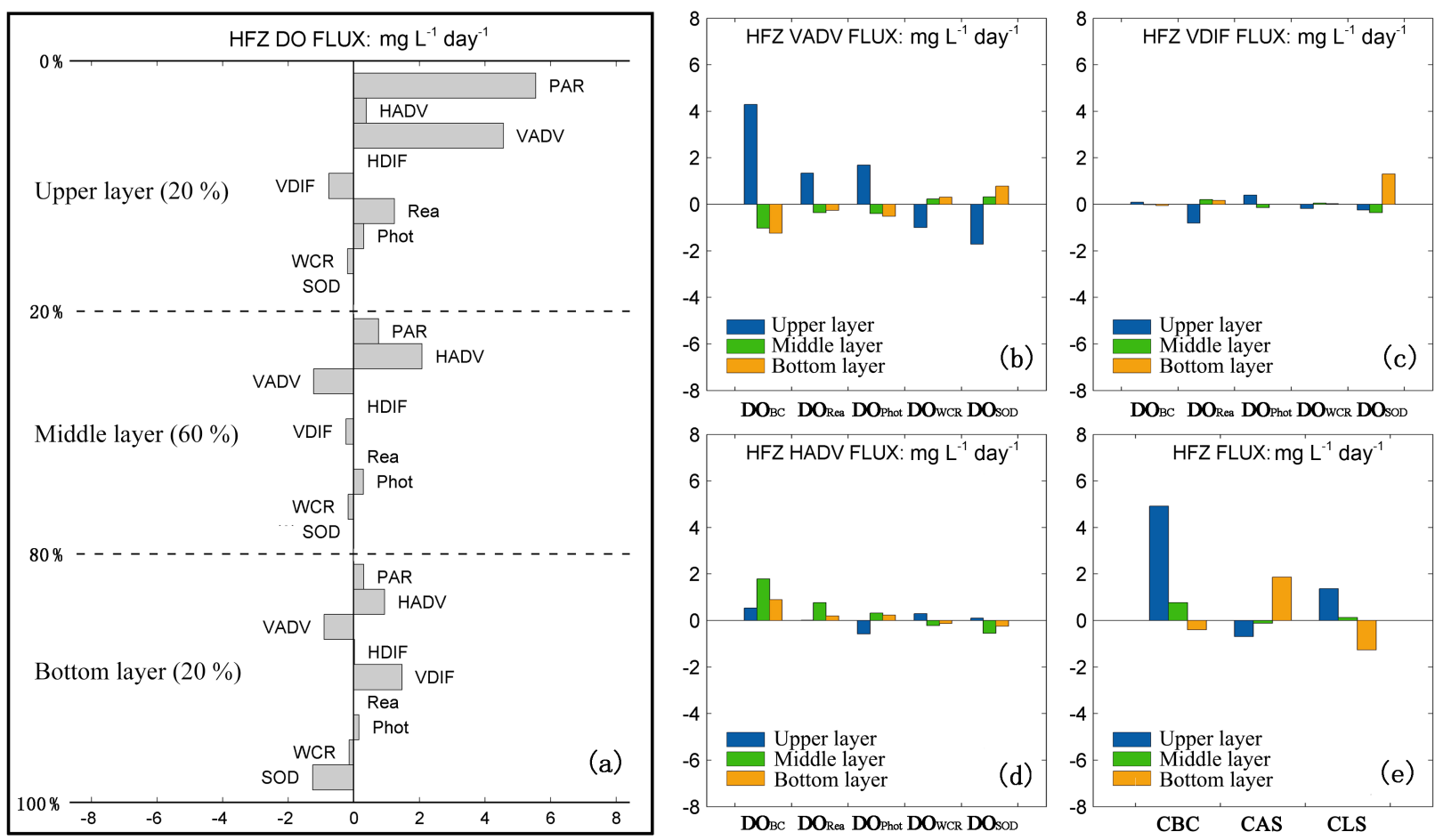

Figure 12. Same as Fig. 11 except for the HFZ.

\subsubsection{HFZ}

Compared with the upper layer in the PRE, the vertical advective DO fluxes in the HFZ are almost 5.5-fold larger because of its shallower depth and larger vertical velocity. As a result, vertical advection becomes the most important process controlling the DO balance at the upper layer (Fig. 12a). Besides vertical advection, re-aeration is another important source for DO. In the HFZ, re-aeration brings about $1.24 \mathrm{mg} \mathrm{L}^{-1}$ day $^{-1}$ oxygen to the upper layer (Fig. 12a), $64 \%$ of which is transported to the middle layer via vertical diffusion (Fig. 12c).

At the middle layer, the DO is mainly balanced by horizontal and vertical advection (Fig. 12a), both of which are mainly contributed by boundary conditions (Fig. 12b, d).

At the bottom layer, SOD dominates the DO depletion rate (Fig. 12a) and leads to a significant vertical DO gradient between the middle and bottom layers, which results in $88 \%$ of vertical diffusive DO fluxes (Fig. 12c). In addition, SOD can affect DO concentrations at the upper layer through vertical advection (Fig. 12b). Unlike the bottom layer of the PRE, boundary conditions play a more important role in the DO balance at the bottom layer of the HFZ through horizontal and vertical advection. According to Fig. $12 \mathrm{~b}$ and d, horizontal advection brings $\mathrm{DO}_{\mathrm{BC}}$ to the bottom layer of the HFZ, while vertical advection transports $\mathrm{DO}_{\mathrm{BC}}$ upward to the middle layer. However, these two processes compensate for each other and the DO balance at the bottom layer is mainly con- trolled by CAS and CLS (Fig. 12e). Therefore, the processes controlling the DO balance at the bottom layer of the HFZ and the PRE are basically similar, suggesting the need for further discussion on the mechanisms of hypoxia in the PRE.

\subsection{Why does hypoxia occur in the HFZ?}

Zhang and $\mathrm{Li}$ (2010) showed that the distribution of hypoxia in the PRE was related to SOD because of the dominant roles of SOD in the bottom DO depletion rates. However, as shown in Fig. 13a, the HFZ is not located where high SOD is and there is a location shift between the hypoxic zone and the high SOD areas (Zhang and Li, 2010). One possible reason for this shift is the lack of the full consideration of all source and sink processes. Therefore, we will primarily examine the distribution of the gross DO depletion rate at the bottom layer (Fig. 13b).

In fact, it is hard to estimate the gross DO depletion rate since we cannot confirm the thickness affected by SOD. In the Chesapeake Bay (Hong and Shen, 2013; Shen et al., 2013) and northern Gulf of Mexico (Yu et al., 2015b), SOD is characterized by the thickness of the bottom layer to evaluate the contributions to the DO depletion rate, assuming that the bottom water mixes evenly below the pycnocline. In the PRE, the depth of pycnocline significantly varies in time and space, which makes it hard to estimate. As mentioned above, the shallow depth and large vertical velocities make it possible for SOD to affect the surface layer significantly. Therefore, the gross DO depletion rate was alternatively estimated 

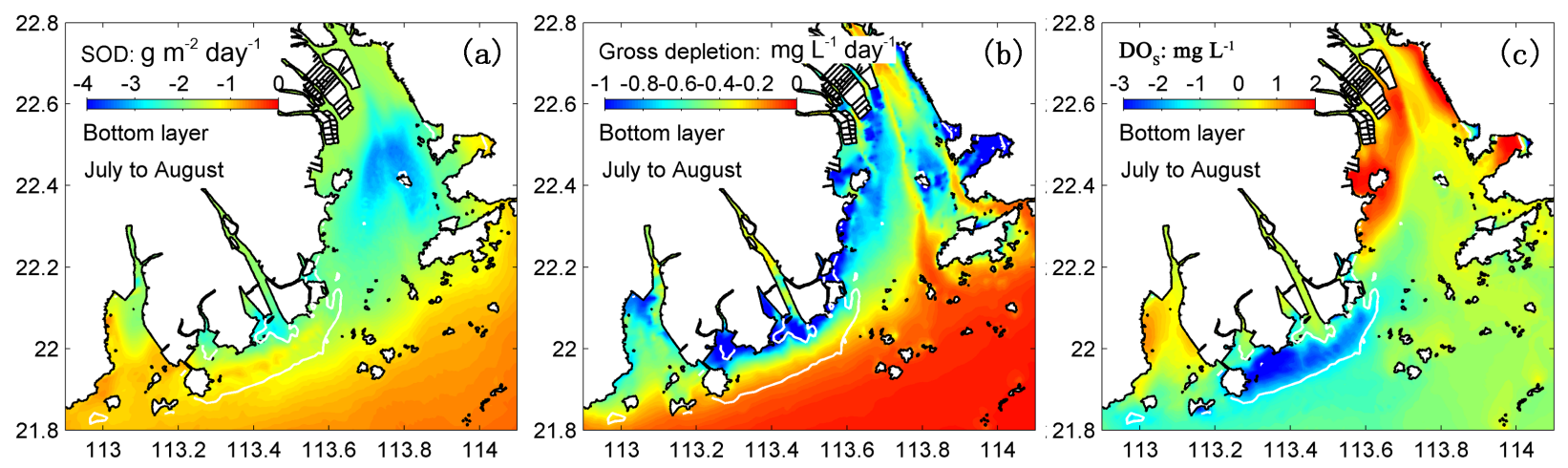

Figure 13. Spatial distributions of the monthly averaged (a) SOD, (b) gross depletion rates of DO, and (c) the concentrations of $\mathrm{DO}_{S}$ at the bottom layer. Note that the HFZ is also shown here (denoted by the area encompassed by white lines).

by summing the WCR, photosynthesis, and SOD, which was divided by depth. The negative values represent DO consumption while the positive values represent DO production. As shown in Fig. 13b, the distribution of hypoxia and the gross DO depletion rate are also inconsistent. Specifically, the gross DO depletion rate ranges from 0.6 to more than $1.0 \mathrm{mg} \mathrm{L}^{-1} \mathrm{day}^{-1}$ in the middle of the Lingdingyang Bay but no hypoxia occurs. In contrast, the gross DO depletion rates are much lower at the bottom layer of the HFZ because the effects of adjacent source and sink processes should be included in the discussion on hypoxia.

Figure 13c shows the agreement in the distribution between $\mathrm{DO}_{S}$ (changes in DO concentrations due to the effects of the source and sink processes; Table 1) and hypoxia with the lowest $\mathrm{DO}_{S}$ areas resembling the HFZ. According to the physical modulation method, $\mathrm{DO}_{S}$ is only controlled by the combination of CAS and CLS. Therefore, hypoxia in the HFZ is caused by the largest negative effect of all source and sink processes occurring not only in local waters but also in adjacent waters, consistent with the diagnostic analysis that the DO balance at the bottom layer is mainly controlled by CAS and CLS. Based on this result, we will continue to investigate why the source and sink processes exert the largest negative effect on the HFZ.

The spatial distribution of $\mathrm{DO}_{\mathrm{SOD}}$ (changes in $\mathrm{DO}$ concentrations due to the effects of SOD), $\mathrm{DO}_{\mathrm{WCR}}, \mathrm{DO}_{\text {Rea }}$, and $\mathrm{DO}_{\text {Phot }}$ are shown in Fig. 14. Because of the similar distributions and magnitudes of $\mathrm{DO}_{\mathrm{WCR}}$ and $\mathrm{DO}_{\mathrm{Phot}}$, the distribution of hypoxia is mainly controlled by re-aeration

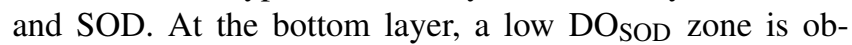
served along the west coast, extending from the west of the lower Lingdingyang Bay to the HFZ where the JulyAugust-averaged $\mathrm{DO}_{\mathrm{SOD}}$ concentration ranges from -4 to $-5 \mathrm{mg} \mathrm{L}^{-1}$ (Fig. 14a). Therefore, the July-August-averaged DO concentration can be decreased by 4 to $5 \mathrm{mg} \mathrm{L}^{-1}$ due to the effects of SOD, causing the west of lower Lingdingyang Bay and HFZ to potentially become hypoxic. The reasons for no occurrence of hypoxia to the west of the lower
Lingdingyang Bay is related to re-aeration. Figure 14c shows that at the bottom layer, re-aeration has distinct positive effects to the west of the lower Lingdingyang Bay, which offsets the high negative effects of SOD there. As a result, only the HFZ is conducive to hypoxia. Additional numerical experiments suggest that turning off re-aeration will lead to a significant expansion of the hypoxic area by more than 9 times to $2203 \mathrm{~km}^{2}$ and result in a shift of the hypoxic centre to the west of the lower Lingdingyang Bay (Fig. 15b, d). Compared to re-aeration and SOD, photosynthesis and WCR had relatively small impacts on DO conditions; turning off these two processes increased the hypoxic area to $591 \mathrm{~km}^{2}$ (Fig. 15a, c). One interesting question remains unclear: why does re-aeration have the largest positive effects to the west of the lower Lingdingyang Bay?. In order to investigate this question, the $\mathrm{DO}_{\text {Rea }}$ balance analysis is conducted for this area (the western shoal near Qi' ao Island and encompassed by a DO Rea isoline of $4 \mathrm{mg} \mathrm{L}^{-1}$, as shown in Fig. 14c) (Fig. 14e-g). As shown in Fig. 14e, there is a high oxygen influx driven by re-aeration in the upper layer (blue arrow in Fig. 14e), among which the vast majority (76\%) is transported to the middle layer (red arrow in Fig. 14e) and eventually $21 \%$ reaches the bottom layer (red arrow in Fig. 14g) through vertical diffusion. In addition, due to the high reaeration rate on the surface of the upper Lingdingyang Bay, the horizontal advection brings about $0.31 \mathrm{mg} \mathrm{L}^{-1}$ day $^{-1} \mathrm{DO}$ originating from the upstream re-aeration (green arrow in Fig. 14g). Since the supplement brought by vertical diffusion and horizontal advection exceeds the loss caused by vertical advection, there remains a considerable amount of oxygen originating from surface re-aeration. In the HFZ, the reaeration rate is 0.39 times lower; therefore, the vertical diffusive $\mathrm{DO}_{\mathrm{Rea}}$ flux to the bottom layer is only one-fourth of the value to the west of Lingdingyang Bay estuary. Finally, no hypoxia occurs in the upper Lingdingyang Bay because it is adjacent to the river network and influenced by river discharges largely. As a result, the quick water exchange here brings low-DO freshwater out of the upper Lingdingyang 

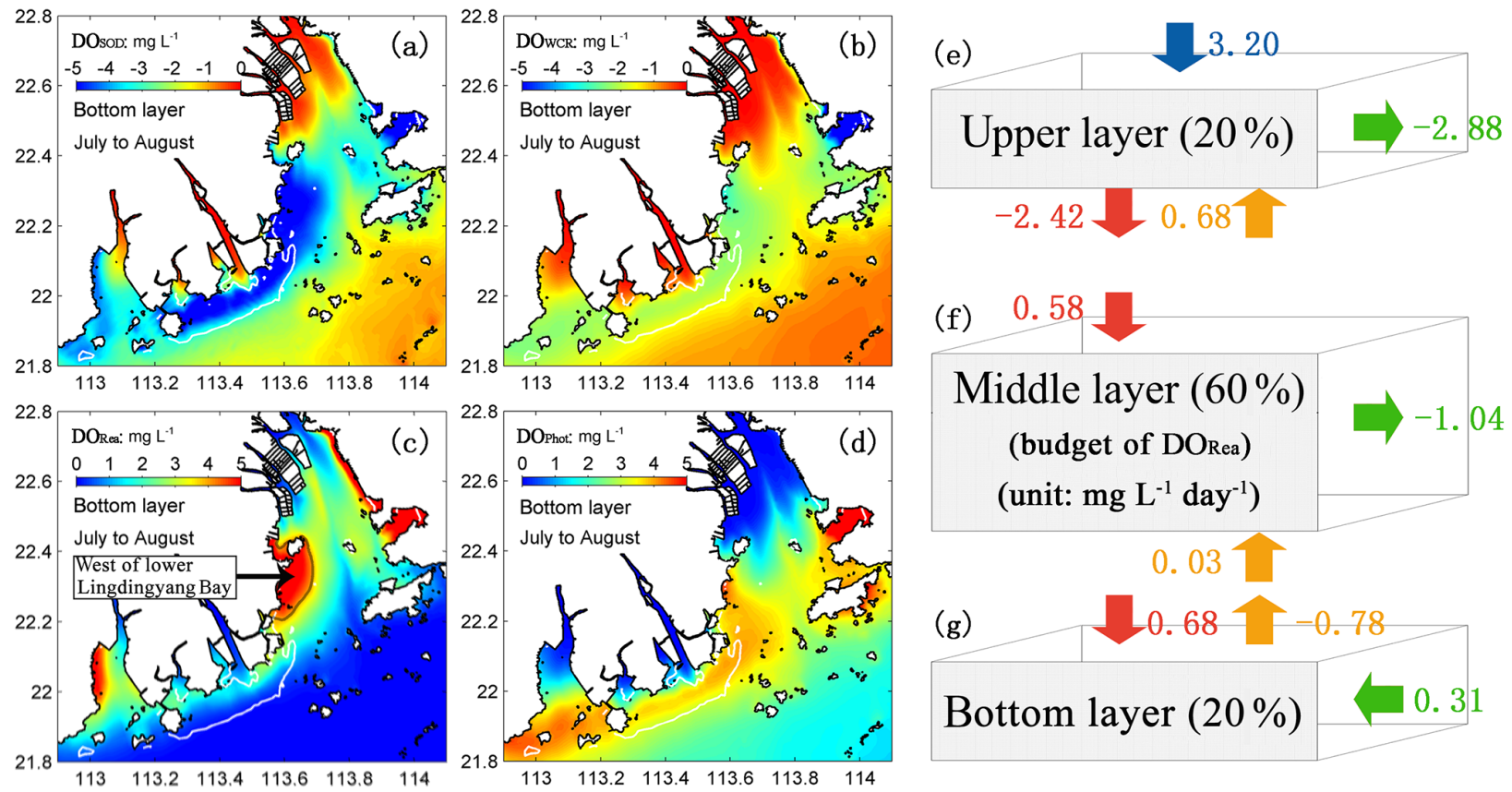

(f)

0.58

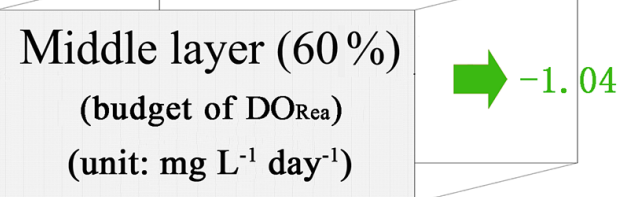

(g) 0.03

g) -0.68

Bottom layer (20\%) $\quad 0.31$

Figure 14. Spatial distributions of the monthly averaged (a) $\mathrm{DO}_{\mathrm{SOD}}$, (b) $\mathrm{DO}_{\mathrm{WCR}}$, (c) $\mathrm{DO}_{\mathrm{Rea}}$, and (d) DOPhot at the bottom layer. Note that the HFZ is also shown here (denoted by the area encompassed by white lines). The DORea balance analysis for (e) the upper layer, (f) the middle layer, and (g) the bottom layer to the west of the lower Lingdingyang Bay (the western shoal near Qi' ao Island and encompassed by a $\mathrm{DO}_{\mathrm{Rea}}$ isoline of $4 \mathrm{mg} \mathrm{L}^{-1}$; as shown in c). Blue arrows represent the re-aeration rates; red arrows represent the vertical diffusive fluxes of $\mathrm{DO}_{\mathrm{Rea}}$; orange arrows represent the vertical advective fluxes of $\mathrm{DO}_{\mathrm{Rea}}$; green arrows represent the horizontal advective fluxes of $\mathrm{DO}_{\mathrm{Rea}}$. Note that positive values indicate sources of DO, while negative values indicate sinks of DO (unit: $\mathrm{mg} \mathrm{L}^{-1} \mathrm{day}^{-1}$ ).

Bay quickly, making it difficult for hypoxia to occur. This can be demonstrated by the high gross DO depletion rates and low $\mathrm{DO}_{S}$ concentration levels at the bottom layer of the upper Lingdingyang Bay (Fig. 13b, c).

\subsection{Why is the hypoxia in the PRE not severe?}

Unlike persistent and extensive hypoxia in the Chesapeake Bay (Hagy et al., 2004) and northern Gulf of Mexico (Rabouille et al., 2008), hypoxia in the PRE is intermittent and confined to small areas. Previous studies suggested that it is because the short residence time (3-5 days) in the PRE prevents the organic matter from completing their biogeochemical cycle (Yin et al., 2004; Rabouille et al., 2008). Moreover, the phosphorus limitation and high turbidity also inhibit the complete utilization of nutrients and growth of phytoplankton in the PRE (Yin et al., 2004).

However, according to Zhang and Li (2010), hypoxia in the PRE is mainly controlled by SOD, which is mainly determined by terrestrial particulate organic matter. In addition, we also compared the gross depletion rate in the PRE with that in the northern Gulf of Mexico and Chesapeake Bay (Table 4). In the northern Gulf of Mexico, SOD ranges from 0.06 to $0.70 \mathrm{~g} \mathrm{~m}^{-2} \mathrm{day}^{-1}$ during the summer of 2003 2006 and the net water column respiration (estimated by multiplying the WCR and photosynthesis by the depth below the pycnocline) ranges from 0.57 to $3.60 \mathrm{~g} \mathrm{~m}^{-2} \mathrm{day}^{-1}$ below the pycnocline. Given the depth below the pycnocline is 8.8 to $22.8 \mathrm{~m}$, the gross depletion rate ranges from 0.11 to $0.55 \mathrm{mg} \mathrm{L}^{-1} \mathrm{day}^{-1}$, with the areal extent of hypoxia averaged $13500 \mathrm{~km}^{2}$. In the summer in the Chesapeake Bay, the gross depletion rate ranges from 0.16 to $0.96 \mathrm{mg} \mathrm{L}^{-1}$ day $^{-1}$ in the main stem of the bay and the persistent hypoxia extends for $8 \mathrm{~km}^{3}$. In the HFZ, the model results (Fig. 13b) show that the gross depletion ranges from less than 0.2 to more than $1.0 \mathrm{mg} \mathrm{L}^{-1}$ day $^{-1}$ with the hypoxic area and hypoxic volume of $237 \mathrm{~km}^{2}$ and $0.13 \mathrm{~km}^{3}$, respectively. These comparisons show that the gross DO depletion rates are comparable to or even higher while hypoxia is less severe in the PRE compared to the Chesapeake Bay and the northern Gulf of Mexico. Therefore, there should be a different mechanism rather than phosphorous limitation or high concentrations of sediments controlling the hypoxia in the Pearl River estuary.

As mentioned earlier, hypoxia is confined within the HFZ due to the effects of SOD and re-aeration. When we focus on hypoxia in the HFZ, relatively high DO concentrations are caused by the mild effects of source and sink processes on DO. According to Fig. 13c, the July-August-averaged $\mathrm{DO}_{S}$ concentration ranges from -2 to $-3 \mathrm{mg} \mathrm{L}^{-1}$ at the bottom layer of HFZ, which indicates that July-August-averaged DO concentration varies from 3 to $4 \mathrm{mg} \mathrm{L}^{-1}$ given that the July-August-averaged $\mathrm{DO}_{\mathrm{BC}}$ concentration is approximately 

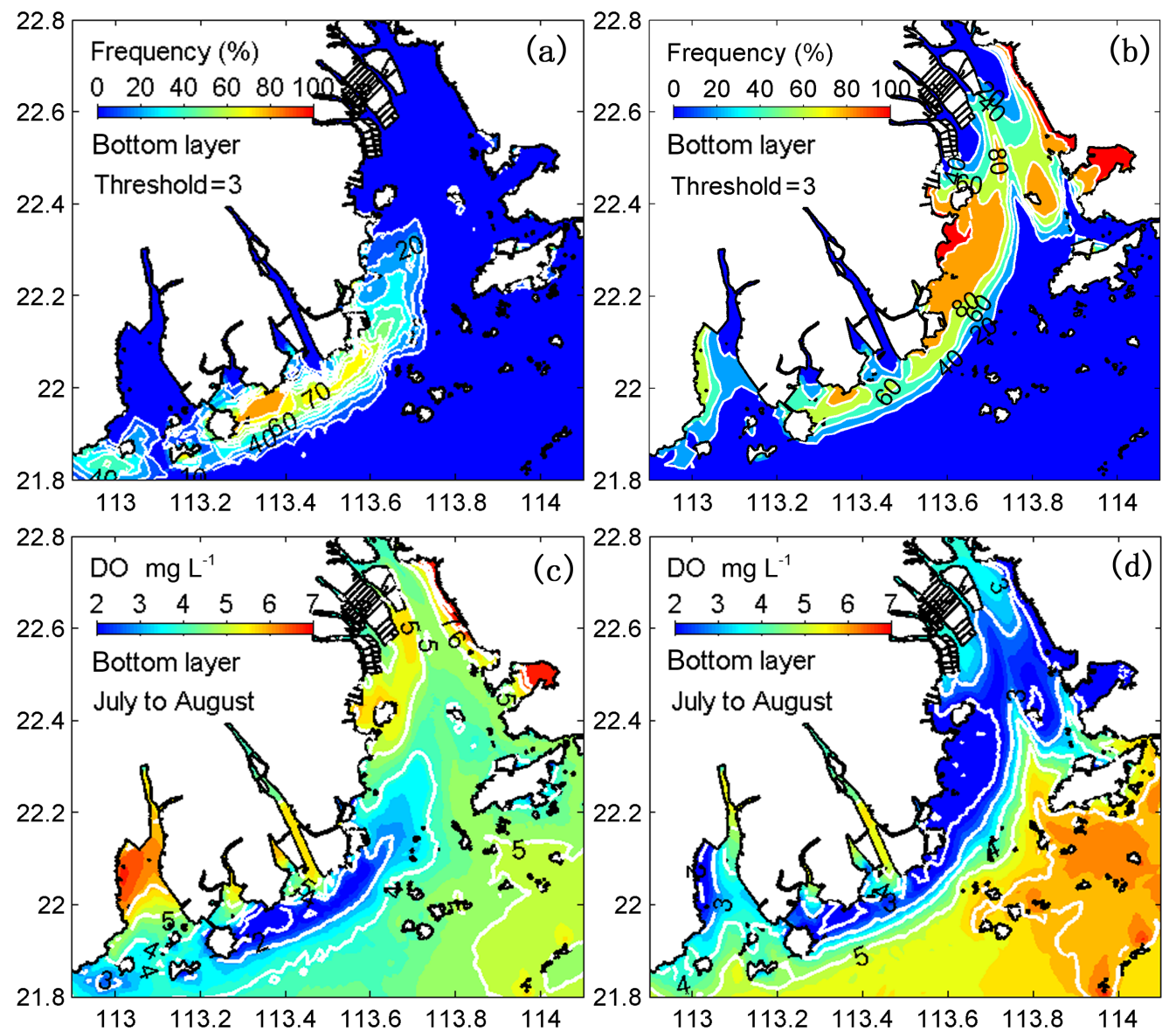

Figure 15. Spatial distributions of hypoxic frequency (using a DO threshold of $3 \mathrm{mg} \mathrm{L}^{-1}$ for hypoxia) and the monthly averaged DO concentrations at the bottom layer for the numerical experiments by turning off (a, c) photosynthesis and water column respiration and (b, d) the re-aeration, respectively.

Table 4. A summary of the sediment oxygen demand (SOD), net water column respiration rate (NWCR, estimated by multiplying WCR and photosynthesis by the depth below the pycnocline), and gross depletion rate (GD) below the pycnocline reported for the northern Gulf of Mexico and the Chesapeake Bay. Note that negative values represent DO consumption rates. The thickness of the bottom layer below the pycnocline and the hypoxic estimations for these two regions are also included.

\begin{tabular}{|c|c|c|c|c|c|c|}
\hline & $\begin{array}{l}\text { Time } \\
\text { period }\end{array}$ & $\begin{array}{l}\text { SOD } \\
\left(\mathrm{g} \mathrm{m}^{-2} \mathrm{day}^{-1}\right)\end{array}$ & $\begin{array}{l}\text { NWCR } \\
\left(\mathrm{g} \mathrm{m}^{-2} \mathrm{day}^{-1}\right)\end{array}$ & $\begin{array}{l}\text { GD } \\
\left(\mathrm{mg} \mathrm{L}^{-1} \mathrm{day}^{-1}\right)\end{array}$ & $\begin{array}{l}\text { Depth of the } \\
\text { bottom layer }(m)\end{array}$ & $\begin{array}{r}\text { Hypoxic area } \\
\text { or volume }\end{array}$ \\
\hline Northern Gulf of Mexico & $\begin{array}{l}\text { Jun } 2003^{\mathrm{a}} \\
\text { Jun } 2006^{\mathrm{a}} \\
\text { Aug } 2007^{\mathrm{a}}\end{array}$ & $\begin{array}{l}-0.06 \text { to }-0.70 \\
-0.06 \text { to }-0.58 \\
-0.06 \text { to }-0.53\end{array}$ & $\begin{array}{l}-0.57 \text { to }-2.39 \\
-2.69 \text { to }-3.50 \\
-1.06 \text { to }-2.23\end{array}$ & $\begin{array}{l}-0.11 \text { to }-0.24 \\
-0.24 \text { to }-0.33 \\
-0.23 \text { to }-0.55\end{array}$ & $\begin{array}{r}15.0-22.5 \\
18.8-21.4 \\
8.8-22.8\end{array}$ & $13500 \mathrm{~km}^{2 b}$ \\
\hline Chesapeake Bay & $\mathrm{Aug}^{\mathrm{c}}$ & -1.5 to -3.2 & -1.7 to -16.0 & -0.16 to -0.96 & 20 & $8 \mathrm{~km}^{3 \mathrm{~d}}$ \\
\hline
\end{tabular}

${ }^{a}$ Murrell and Lehrter (2011); ${ }^{\mathrm{b}}$ Rabalais et al. (2007); ${ }^{\mathrm{c}}$ Hong and Shen (2013); ${ }^{\mathrm{d}}$ Rabalais et al. (2010)

$6 \mathrm{mg} \mathrm{L}^{-1}$. Based on this result, we will continue to study the reasons for such low $\mathrm{DO}_{S}$ concentrations at the bottom layer of the HFZ.

Figure $14 \mathrm{a}$ reveals that $\mathrm{DO}_{\mathrm{SOD}}$ ranges from -4 to $-5 \mathrm{mg} \mathrm{L}^{-1}$ at the bottom layer of the HFZ, with the spatially averaged value of $-4.31 \mathrm{mg} \mathrm{L}^{-1}$. This result indicates that the average DO concentrations at the bottom layer of HFZ will be as low as $1.76 \mathrm{mg} \mathrm{L}^{-1}$, assuming that other source and sink processes are neglected. This result implies that SOD alone is large enough to form severe hypoxia in HFZ. However, photosynthesis production rates exceed the WCR consumption rate and eventually increase the average DO con- 


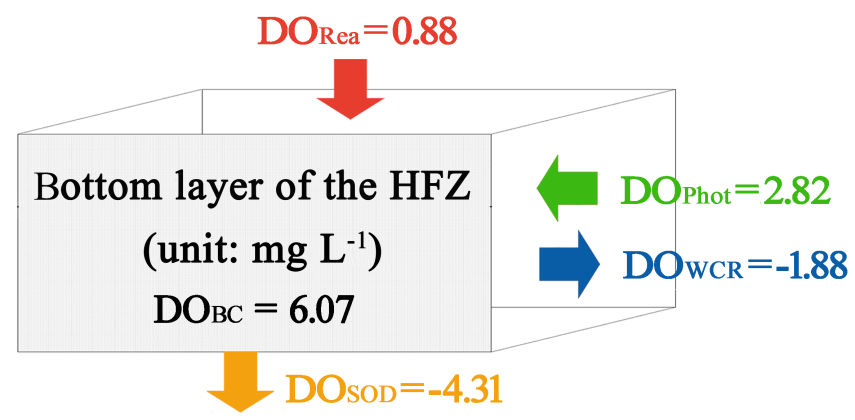

Figure 16. The simulated mass balance for the bottom DO in the HFZ. Note that positive values indicate positive effects on the DO concentrations, while negative values indicate negative effects (unit: $\left.\operatorname{mg~L}{ }^{-1}\right)$.

centrations significantly by $0.94 \mathrm{mg} \mathrm{L}^{-1}$ at the bottom layer of HFZ (Fig. 16). Numerical experiments showed that turning off photosynthesis and WCR decreased DO concentrations to below $3 \mathrm{mg} \mathrm{L}^{-1}$ and increased the hypoxic frequency to more than $60 \%$ in HFZ (Fig. 15a, c). In addition to photosynthesis, re-aeration is another important source of DO, which can cause an increase in average DO concentrations by $0.88 \mathrm{mg} \mathrm{L}^{-1}$ at the bottom layer of the HFZ (Fig. 16). As shown in Fig. 15, turning off re-aeration can also decrease the DO concentrations and increase the hypoxic frequency at the bottom layer of the HFZ. Moreover, the hypoxic frequency averaged over the bottom layer of the HFZ was increased to about $59 \%$; thus, hypoxia would occur for over a month during July and August in the HFZ. Therefore, there are two reasons for hypoxia not being severe in the PRE. First, the hypoxic area is limited due to the effects of SOD and re-aeration. Second, the intermittent hypoxia in the HFZ is caused by re-aeration and photosynthesis which offset a portion of DO consumed by SOD.

\section{Summary and conclusions}

We used a physical-biogeochemical coupled model incorporated with the physical modulation method to investigate the DO dynamics and hypoxia during summer in the PRE. Model validations using the available in situ data and historical observations showed that our model could reasonably reproduce the observed patterns of hydrodynamic parameters and DO concentrations as well as the key processes controlling hypoxia (i.e. re-aeration and SOD). In addition, the physical modulation method was able to predict the simulated concentrations and mass budgets of DO from the RCA model and, therefore, could be used to quantify the relative impacts of boundary conditions and source and sink processes occurring in local and adjacent waters on the DO conditions.

The model results showed a high-frequency zone of hypoxia on the shelf off the Modaomen sub-estuary, consistent with previous studies. Hypoxia in the HFZ was confined to a thin layer above the sediment and was not severe because of its intermittency in time and limited spatial extent ascribed to the contributions of re-aeration and photosynthesis. Based on the diagnostic analysis using the physical modulation method, the DO balance at the bottom layer was largely affected by local and adjacent source and sink processes. Re-aeration and SOD were the two principle kinetic processes controlling the spatial distribution and duration of bottom hypoxia in the PRE. SOD could exert significant negative effects on the bottom DO concentrations in the HFZ and to the west of the lower Lingdingyang Bay, making these two areas prone to hypoxia. However, re-aeration along with physical transport could supply a considerable amount of DO to the bottom layer and largely offset the oxygen consumed by SOD. Consequently, no hypoxia occurred to the west of the lower Lingdingyang Bay, while hypoxia in the HFZ was intermittent and confined to a smaller area compared to those in the Chesapeake Bay and the northern Gulf of Mexico. Furthermore, our numerical experiments suggested that turning off re-aeration could produce a larger, more persistent hypoxic area in the PRE.

Finally, the physical modulation method proposed in this study could be useful for further investigation of other water quality issues in the PRE and could also be applied to other shallow and river-dominated estuaries.

Data availability. Data of water levels used for model validation are obtained from the Guangdong Hydrological Bureau. Data of salinity, temperature, and dissolved oxygen are based on the cruise observations obtained from the National 908 project and the 908 Project of Guangdong Province. All data used to generate figures can be assessed publicly at http://wemt_number1.pc.goabc.cn/ wemt_number1/vip_doc/4712454.html.

Competing interests. The authors declare that they have no conflict of interest.

Acknowledgements. This work was supported by the National Natural Science Foundation of China (grant no. 41306105), the Guangdong Natural Science Foundation (grant no. 2014A030313169), the Science and Technology Planning Project of Guangdong Province, China (grant no. 2014A020217003), and the Fundamental Research Funds for the Central Universities (grant no. 131gpy59).

Edited by: C. Robinson

Reviewed by: three anonymous referees 


\section{References}

Boynton, W. and Kemp, W. M.: Nutrient regeneration and oxygen consumption by sediments along an estuarine salinity gradient, Mar. Ecol.-Prog. Ser., 23, 45-55, 1985.

Cai, S. Q., Zheng, S., and Wei, X.: Progress on the hydrodynamic characteristics and the hypoxia phenomenon in the Pearl River Estuary, J. Trop. Oceanog., 32, 1-8, 2013 (in Chinese with English abstract).

Chen, J. C., Heinke, G. W., and Zhou, M. J.: The Pearl River Estuary Pollution Project (PREPP), Cont. Shelf Res., 24, 1739-1744, 2004.

Di Toro, D. M.: Optics of turbid estuarine waters: Approximations and applications, Water Res., 12, 1059-1068, 1978.

Di Toro, D. M.: Sediment flux modeling, Soil Sci., 168, 75-76, 2001.

Du, J. B. and Shen, J.: Decoupling the influence of biological and physical processes on the dissolved oxygen in the Chesapeake Bay, J. Geophys. Res.-Oceans, 120, 78-93, 2015.

Guan, W. B., Wong, L. A., and Xu, D.: Modeling nitrogen and phosphorus cycles and dissolved oxygen in the Zhujiang River Estuary, part II:Model development, Acta Oceanol. Sin., 20, 504514, 2001a.

Guan, W. B., Wong, L. A., and Xu, D.: Modeling nitrogen and phosphorus cycles and dissolved oxygen in the Zhujiang River Estuary, part I: Model results, Acta Oceanol. Sin., 20, 493-504, 2001b.

Guo, W., Ye, F., Xu, S., and Jia, G.: Seasonal variation in sources and processing of particulate organic carbon in the Pearl River estuary, South China, Estuar. Coast. Shelf S., 167, Part B, 540548,2015

Hagy, J. D., Boynton, W. R., Keefe, C. W., and Wood, K. V.: Hypoxia in Chesapeake Bay, 1950-2001: Long-term change in relation to nutrient loading and river flow, Estuaries, 27, 634-658, 2004.

He, B., Dai, M., Zhai, W., Guo, X., and Wang, L.: Hypoxia in the upper reaches of the Pearl River Estuary and its maintenance mechanisms: A synthesis based on multiple year observations during 2000-2008, Mar. Chem., 167, 13-24, 2014.

Hong, B. and Shen, J.: Linking dynamics of transport timescale and variations of hypoxia in the Chesapeake Bay, J. Geophys. Res.Oceans, 118, 6017-6029, 2013.

$\mathrm{Hu}$, J., Li, S., and Geng, B.: Modeling the mass flux budgets of water and suspended sediments for the river network and estuary in the Pearl River Delta, China, J. Marine Syst., 88, 252-266, 2011.

Hu, J. T. and Li, S. Y.: Modeling the massfluxes and transformations of nutrients in the Pearl River Delta, China, J. Marine Syst., 78, 146-167, 2009.

HydroQual, Inc.: A Primer for ECOMSED Version 1.3, HydroQual, Inc., Mahwah, NJ, 2002.

HydroQual, Inc.: User's Guide for RCA (Release 3.0), HydroQual, Inc., Mahwah, NJ, 2004.

Justic, D., Rabalais, N. N., and Turner, R. E.: Simulated responses of the Gulf of Mexico hypoxia to variations in climate and anthropogenic nutrient loading, J. Marine Syst., 42, 115-126, 2003.

Li, Y., Li, M., and Kemp, M.: A budget analysis of bottom-water dissolved oxygen in Chesapeake Bay, Estuar. Coasts, 38, 2132 $2148,2015$.
Liu, D., Hu, J., Li, S., and Huang, J.: Validation and application of a three-dimensional coupled water quality and sediment model of the Pearl River Estuary, Acta Scientiae Circumstantiae, 36, 4025-4036, https://doi.org/10.13671/j.hjkxxb.2016.0145, 2015 (in Chinese with English abstract).

Luo, L., Shi-Yu, L. I., and Wang, D. X.: Modelling of hypoxia in the Pearl River estuary in summer, Adv. Water Sci., 19, 729735, https://doi.org/10.14042/j.cnki.32.1309.2008.05.011, 2008 (in Chinese with English abstract).

Mellor, G. L. and Yamada, T.: Development of a turbulence closure model for geophysical fluid problems, Rev. Geophys., 20, 851875, 1982.

Montes, I., Dewitte, B., Gutknecht, E., Paulmier, A., Dadou, I., Oschlies, A., and Garçon, V.: High-resolution modeling of the Eastern Tropical Pacific oxygen minimum zone: Sensitivity to the tropical oceanic circulation, J. Geophys. Res.-Oceans, 119, 5515-5532, 2014.

Murrell, M. C. and Lehrter, J. C.: Sediment and Lower Water Column Oxygen Consumption in the Seasonally Hypoxic Region of the Louisiana Continental Shelf, Estuar. Coasts, 34, 912-924, 2011.

Ni, X., Huang, D., Zeng, D., Zhang, T., Li, H., and Chen, J.: The impact of wind mixing on the variation of bottom dissolved oxygen off the Changjiang Estuary during summer, J. Marine Syst., 154, 122-130, 2014.

Ou, S., Zhao, H., and Wang, D.: Dynamics of the buoyant plume off the Pearl River Estuary in summer, Environ. Fluid Mech., 9, 471-492, 2009.

Rabalais, N. N., Turner, R. E., Gupta, B. K. S., Boesch, D. F., Chapman, P., and Murrell, M. C.: Hypoxia in the northern Gulf of Mexico: Does the science support the Plan to Reduce, Mitigate, and Control Hypoxia?, Estuar. Coasts, 30, 753-772, 2007.

Rabalais, N. N., Díaz, R. J., Levin, L. A., Turner, R. E., Gilbert, D., and Zhang, J.: Dynamics and distribution of natural and human-caused hypoxia, Biogeosciences, 7, 585-619, https://doi.org/10.5194/bg-7-585-2010, 2010.

Rabouille, C., Conley, D. J., Dai, M. H., Cai, W. J., Chen, C. T. A., Lansard, B., Green, R., Yin, K., Harrison, P. J., Dagg, M., and McKee, B.: Comparison of hypoxia among four river-dominated ocean margins: The Changjiang (Yangtze), Mississippi, Pearl, and Rhône rivers, Cont. Shelf Res., 28, 1527-1537, 2008.

Scavia, D., Rabalais, N. N., Turner, R. E., Justic, D., and Wiseman, W. J.: Predicting the response of Gulf of Mexico hypoxia to variations in Mississippi River nitrogen load, Limnol. Oceanogr., 48, 951-956, 2003.

Scully, M. E.: Wind Modulation of Dissolved Oxygen in Chesapeake Bay, Estuar. Coasts, 33, 1164-1175, 2010.

Shen, J., Hong, B., and Kuo, A. Y.: Using timescales to interpret dissolved oxygen distributions in the bottom waters of Chesapeake Bay, Limnol. Oceanogr., 58, 2237-2248, 2013.

Wang, B.: Hydromorphological mechanisms leading to hypoxia off the Changjiang estuary, Mar. Environ. Res., 67, 53-58, 2009.

Wang, B., Wei, Q., Chen, J., and Xie, L.: Annual cycle of hypoxia off the Changjiang (Yangtze River) Estuary, Mar. Environ. Res., 77, 1-5, 2012.

Ye, H., Chen, C., Sun, Z., Tang, S., Song, X., Yang, C., Tian, L., and Liu, F.: Estimation of the primary productivity in Pearl River Estuary using MODIS data, Estuar. Coasts, 38, 506-518, 2015. 
Yin, K. D., Lin, Z. F., and Ke, Z. Y.: Temporal and spatial distribution of dissolved oxygen in the Pearl River Estuary and adjacent coastal waters, Cont. Shelf Res., 24, 1935-1948, 2004.

Yu, L. Q., Fennel, K., and Laurent, A.: A modeling study of physical controls on hypoxia generation in the northern Gulf of Mexico, J. Geophys. Res.-Oceans, 120, 5019-5039, 2015a.
Yu, L., Fennel, K., Laurent, A., Murrell, M. C., and Lehrter, J. C.: Numerical analysis of the primary processes controlling oxygen dynamics on the Louisiana shelf, Biogeosciences, 12, 2063 2076, https://doi.org/10.5194/bg-12-2063-2015, 2015 b.

Zhang, H. and Li, S. Y.: Effects of physical and biochemical processes on the dissolved oxygen budget for the Pearl River Estuary during summer, J. Marine Syst., 79, 65-88, 2010. 